STUDY OF THE MAIN REASONS FOR THE RELUCTANCE AND OBSTACLES TO ESTABLISHMENT OF RURAL UNEMPLOYED FEMALES OF SMALL PROJECTS AT SOME VILLAGES IN GHARBIA GOVERNORATE

Al-Gamal , M. M. A. ; Rabab W. A. Ghozy and Sally I. M. Younes

Dep of Agricultural extension and Rural development, Faculty of Agricultural, Mansoura University.

دراسـة لأهـم أسبـاب عزوف ومعوقـات إقامـة الريفيـات غيـر العـاملات للمشـروعات

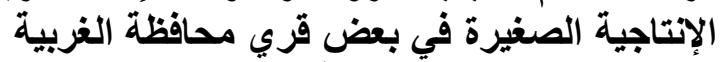

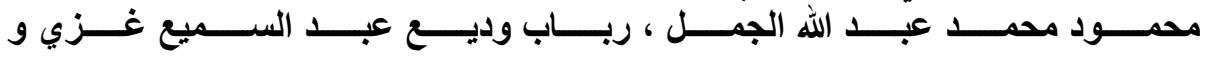

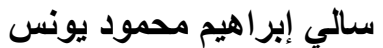
قسم الإرشاد الزراعي والتنمية الريفية ـ كلية الزراعة ـ جامعة المنصورة.

$$
\text { الملخص المَه }
$$

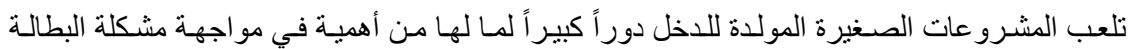

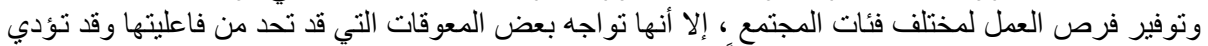

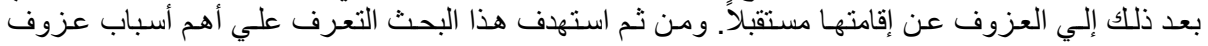

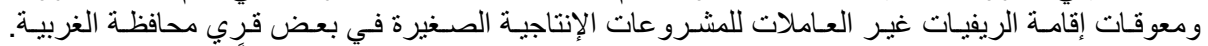

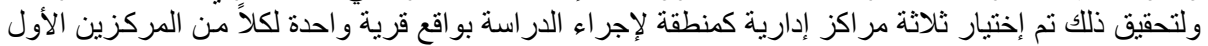

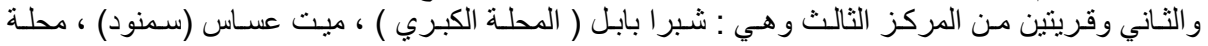

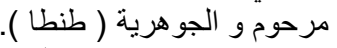
وقد اختيرت العينة بطريقة عشو ائية بإستخدام معادلة Krejcie and Morgan وبنطبيقها تبين

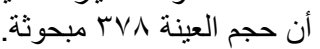

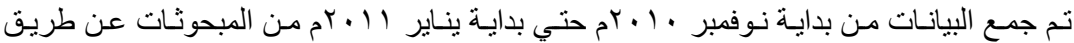

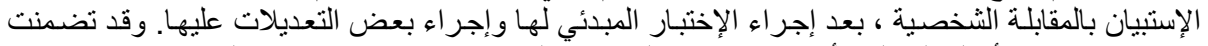

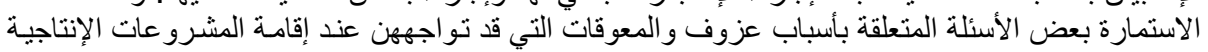

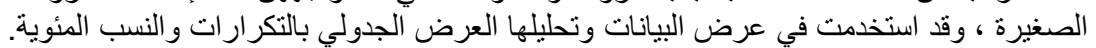

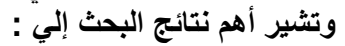

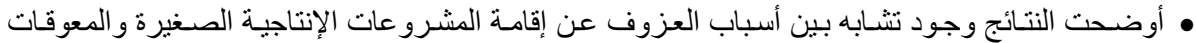

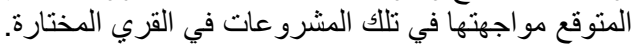

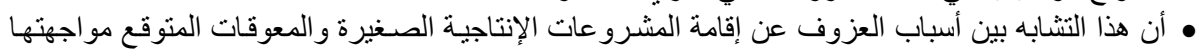

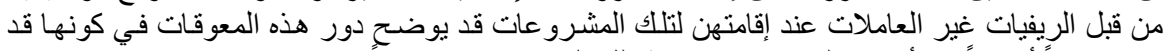

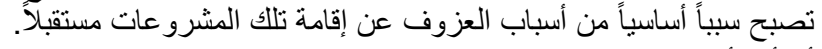

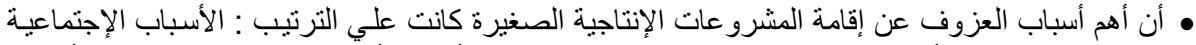

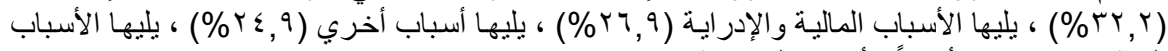

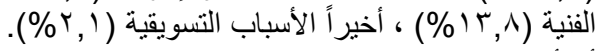

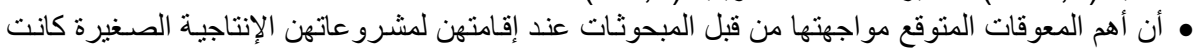

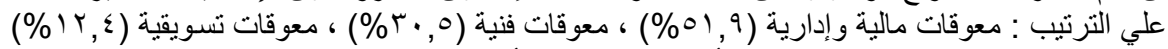

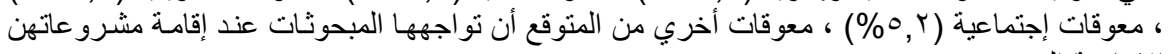

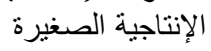

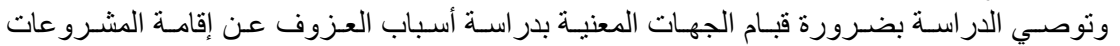

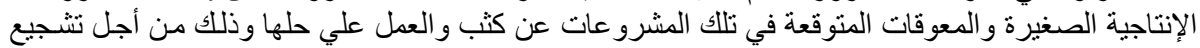

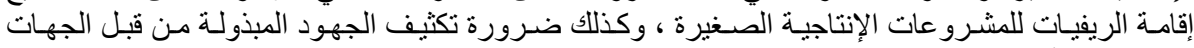

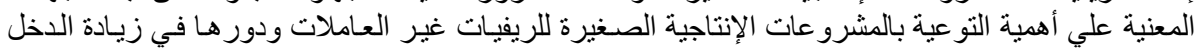




\section{Al-Gamal , M. M. A. et al.}

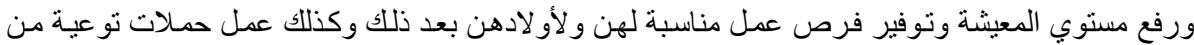

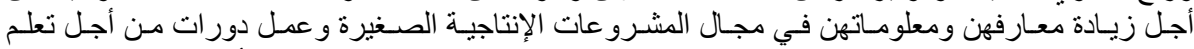

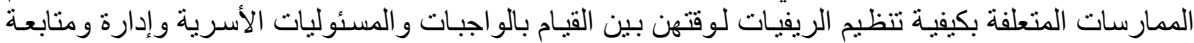
مشرو عاتهن الإنتاجية الصغيرة.

\section{المقدمة والمشكلة البحثية}

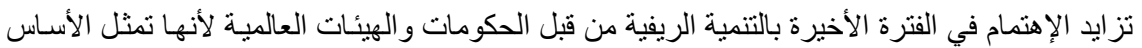

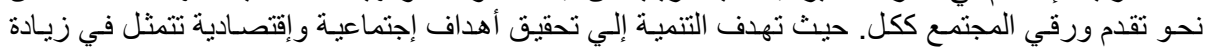

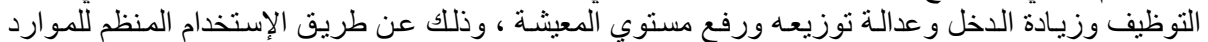

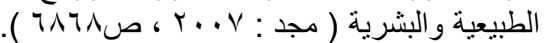

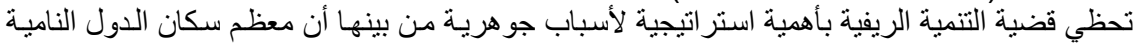

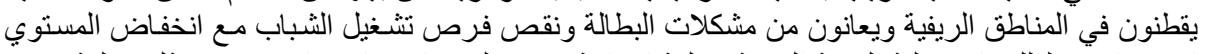

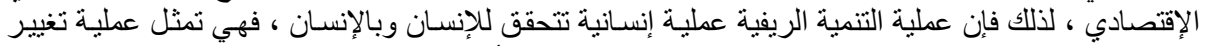

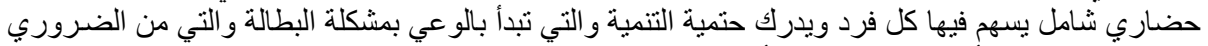

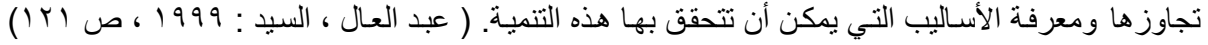
نقلا عن تقرير وزارة الإعلام : 191

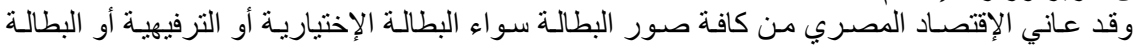

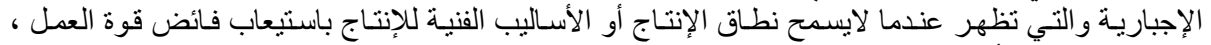

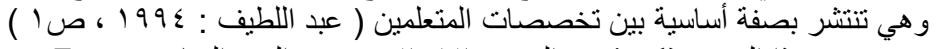

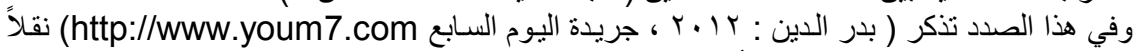

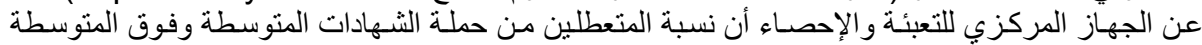

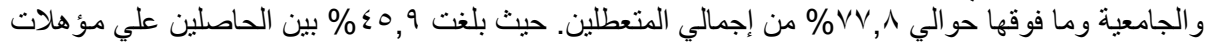

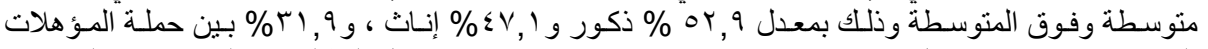

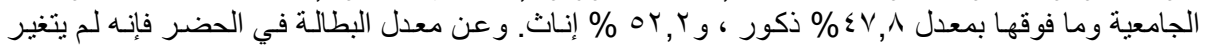

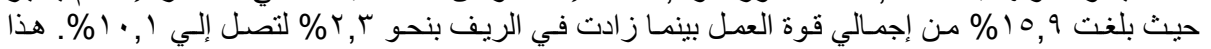

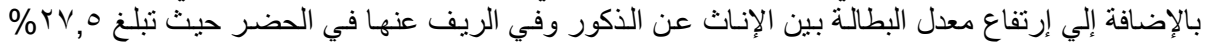

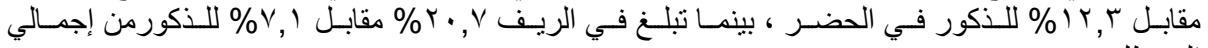

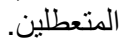

ومن الجدير بالذكر أن البطالة ليست منتشرة بين الإناث فحسب لكنها تدوم لفترات أطول من البطالة بين

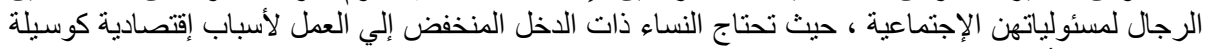

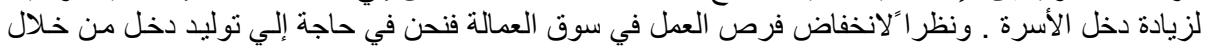

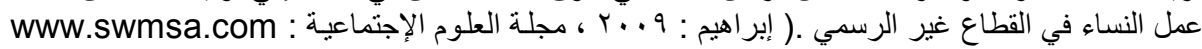

وفي هذا المجال تلعب المشرو عات الصغيرة دوراً هاماً في مجال تتمية المر أة وزيادة دخلها ، لذا تسعي

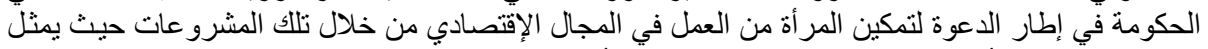

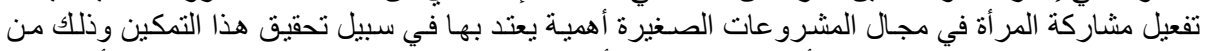

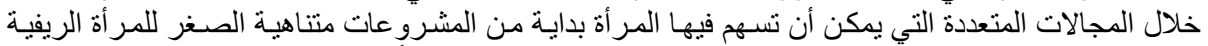

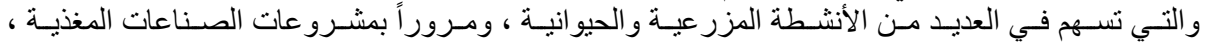

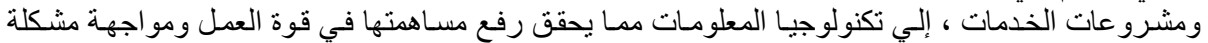

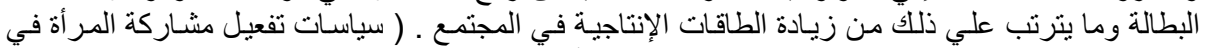

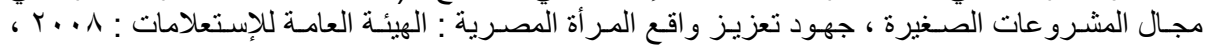

. www.sis.gov.eg

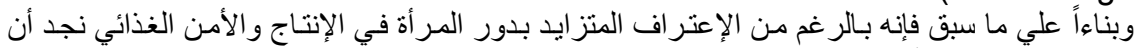

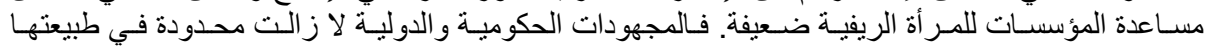

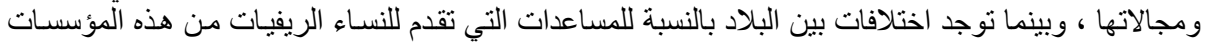

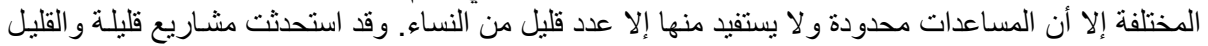

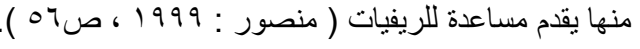




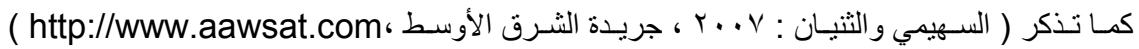

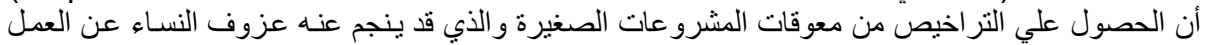

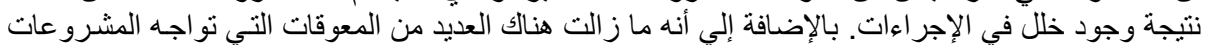

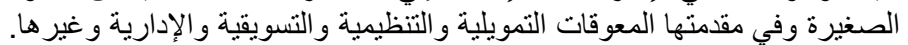

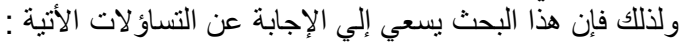

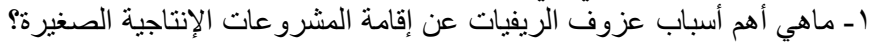

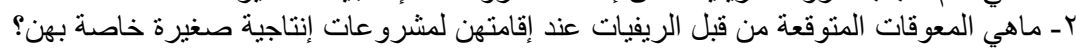

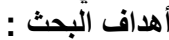

يستهدف هذا البحث بصفة أساسبة التعرف علي أهم أسباب عزوف و ومعوقات إقامة الريفيات غير

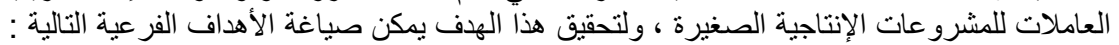

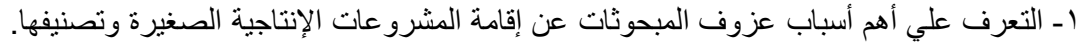

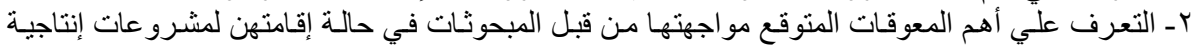
صغيرة.

الإستعراض المرجعي والاراسات السابقة :

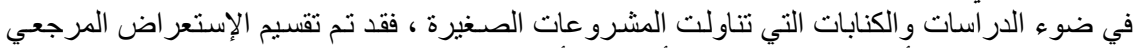

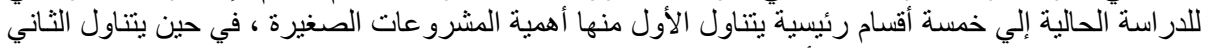

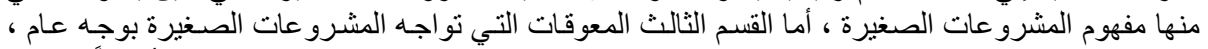

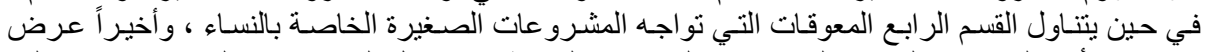

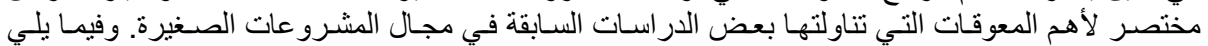
عرض تلك النقاط : ا - أهمية المشروعات الصغيرة :

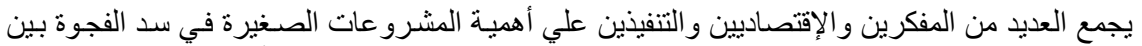

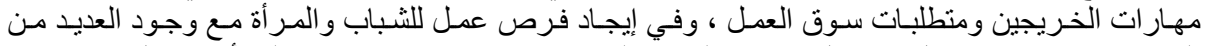

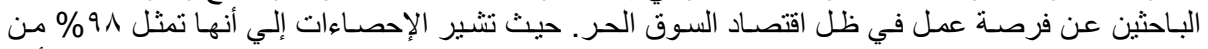

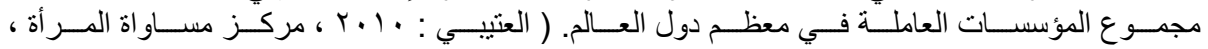
.( http://www.c-we.org

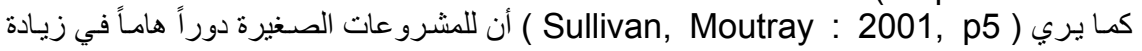

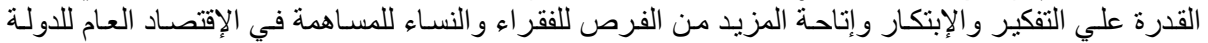

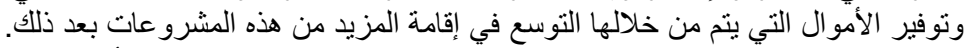

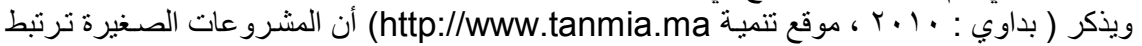

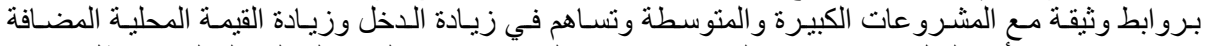

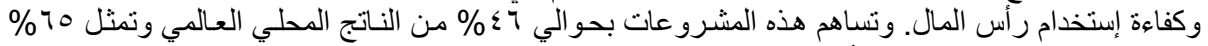

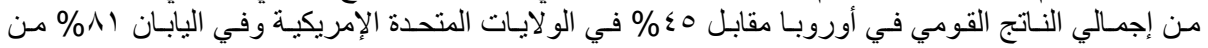

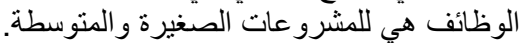

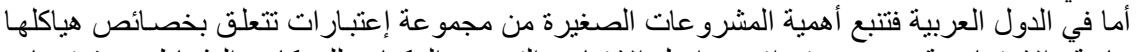

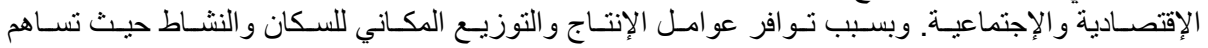

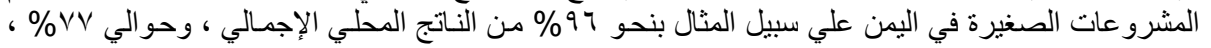

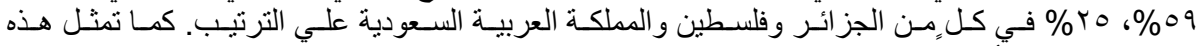

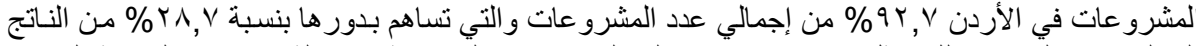

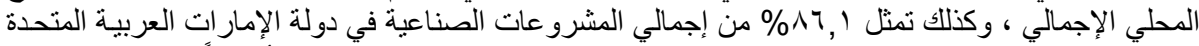

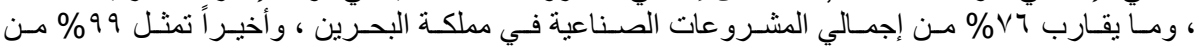

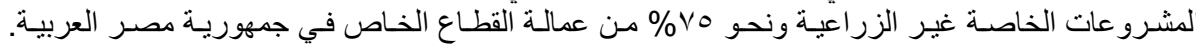

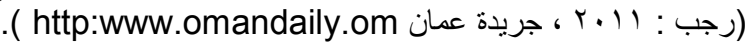

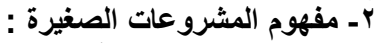

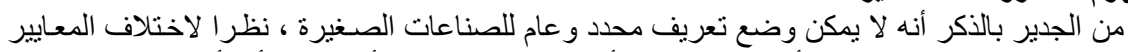

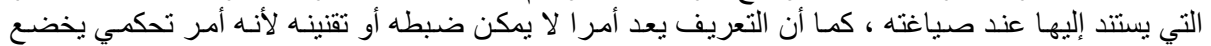

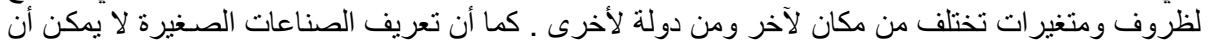




\section{Al-Gamal , M. M. A. et al.}

تقتصر علي معيار العمل و رأس المال بل هناك معايير أخري تأخذ بها بعض الدول كمعيار درجة الانتشـار

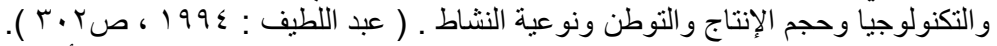

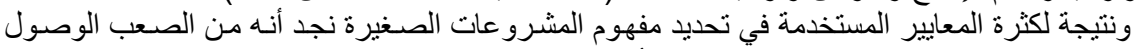

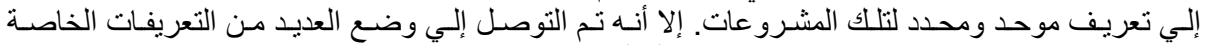
بالمشرو عات الصغيرة والتي اعتمدت علي معيار أو أكثر من المعايير السبابقة.

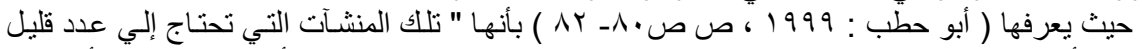

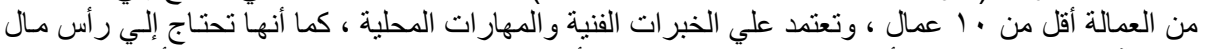

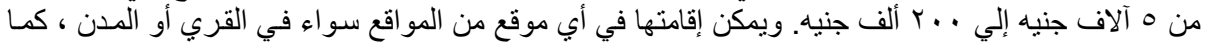

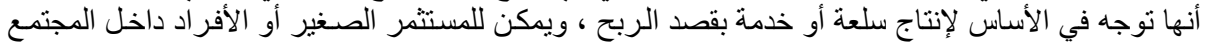

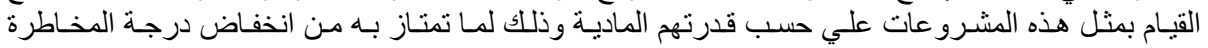

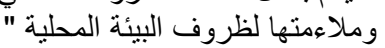

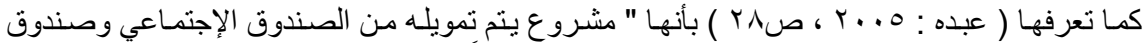

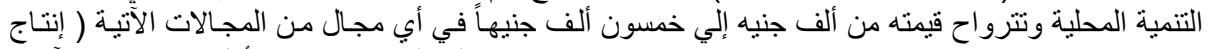
حيو اني - تصنيع - تجاري - خدمي - مهن حرة ) ويكون عدد العمالة بـه من بال بأ فأقل ، ويستخدم الآلات و التكنولوجيا البسيطة.

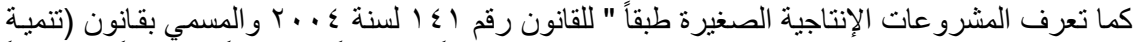

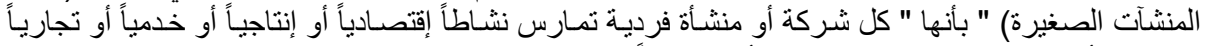

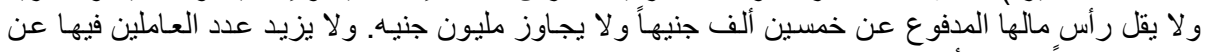

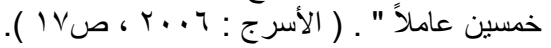

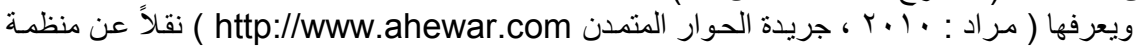

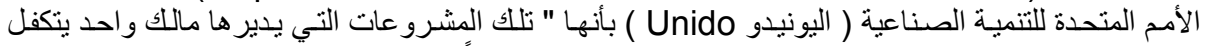

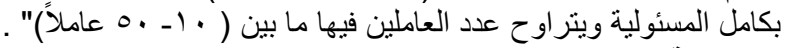

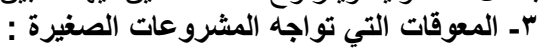

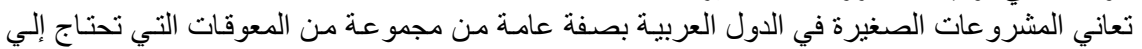

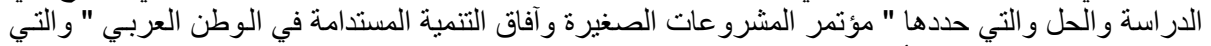

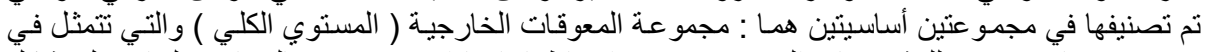

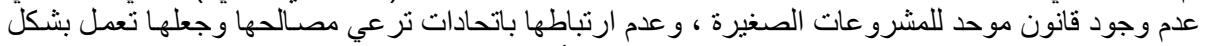

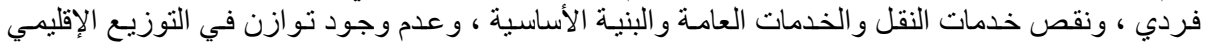

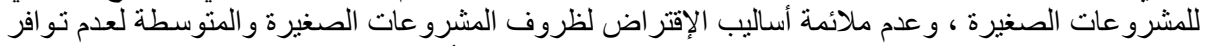

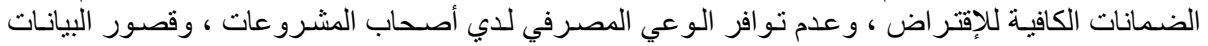

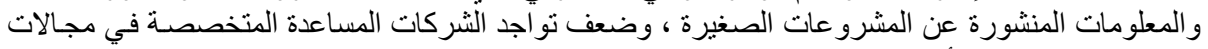

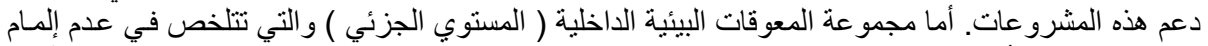

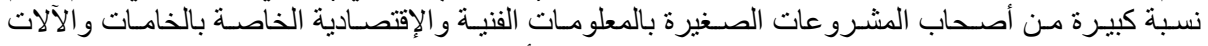

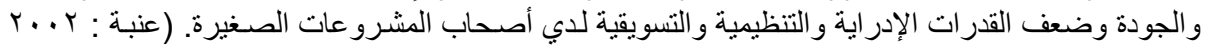

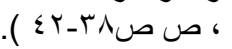

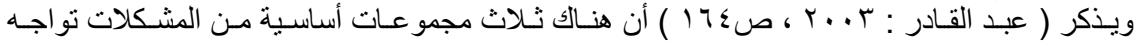

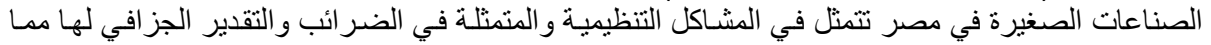

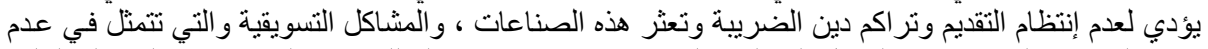

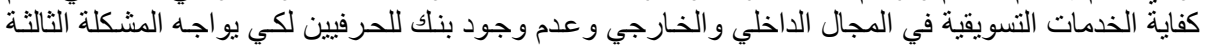

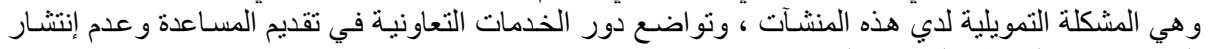
الجمعيات في المناطق الريفية والحضرية.

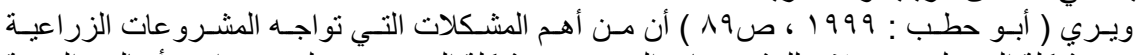

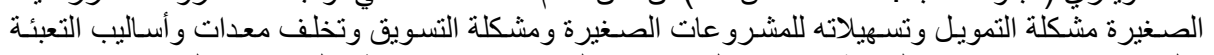

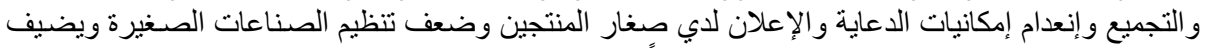

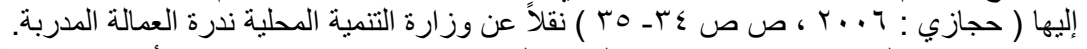

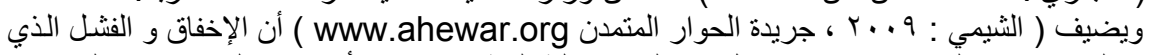

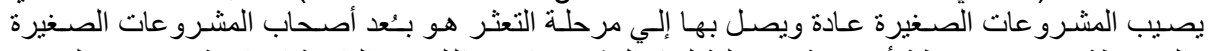

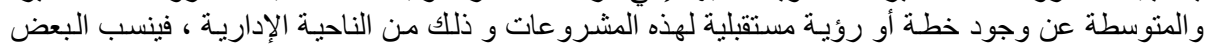




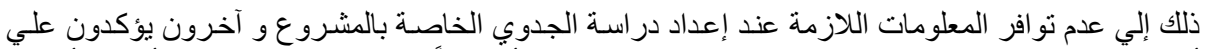

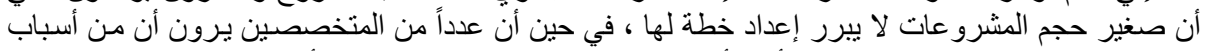

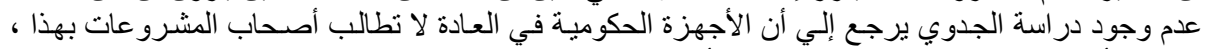

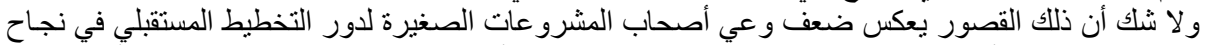

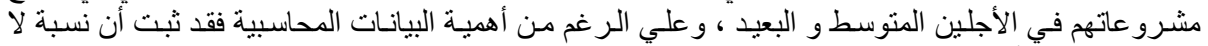

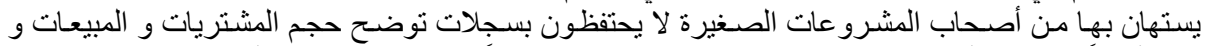

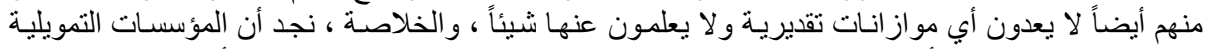

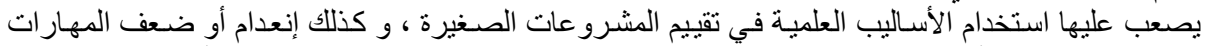

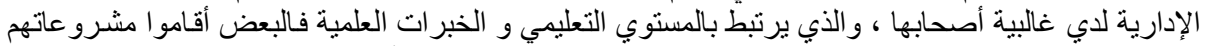

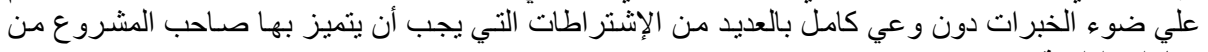
مهار ات إدارية.

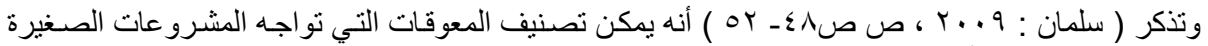

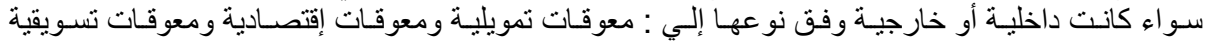
ومعوقات إدارية ومعوقات فنية ومعوقات وفات تنظيمية وتشريعية.

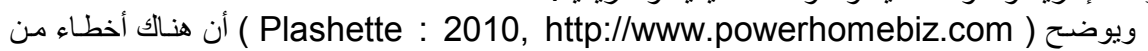

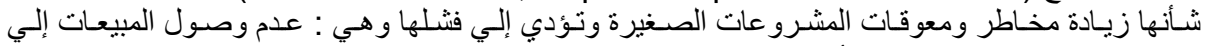

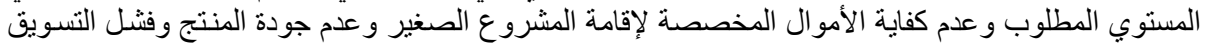

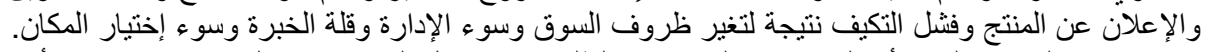

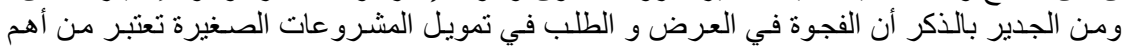

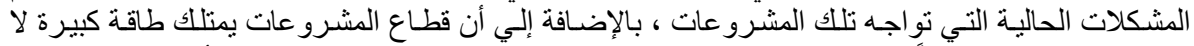

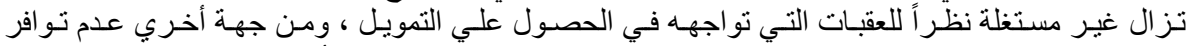

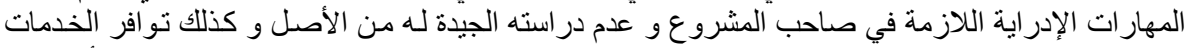

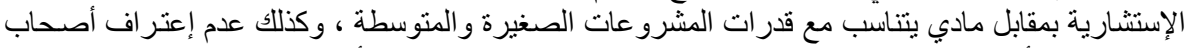

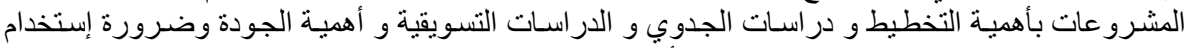

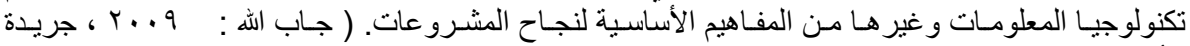

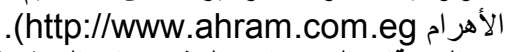

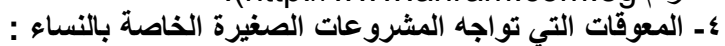

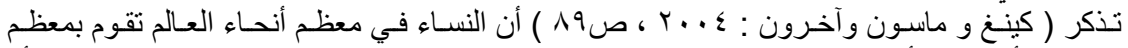

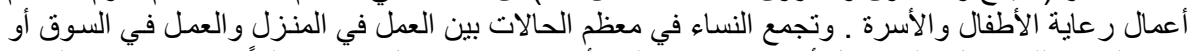

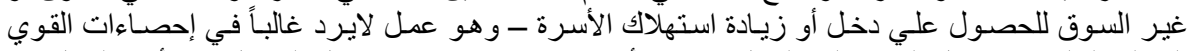

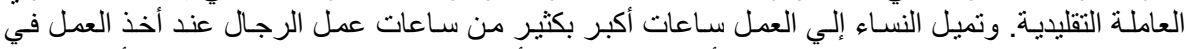

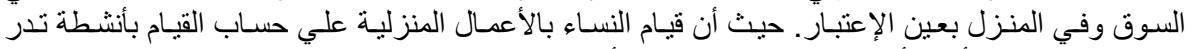

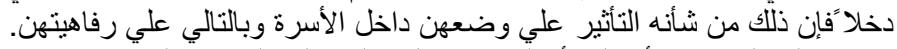

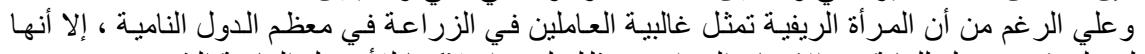

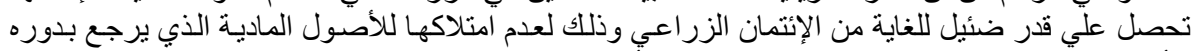

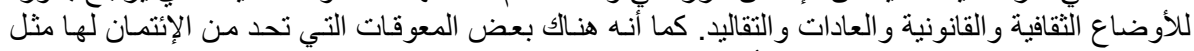

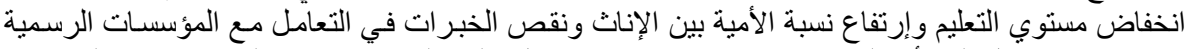

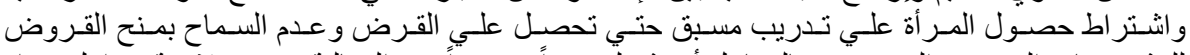

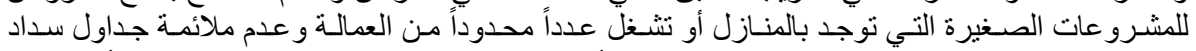

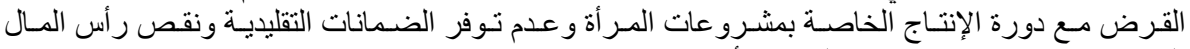

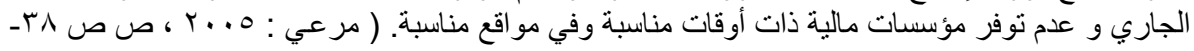

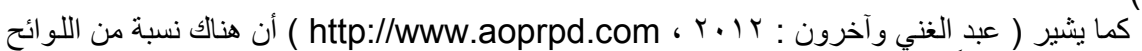

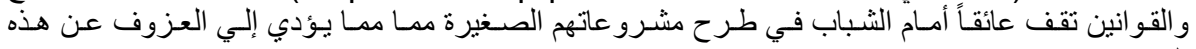

هـ أهم المعوقات التي تناولتها بعض الدراسات السابقة في مجال المشروعات الصغيرة :

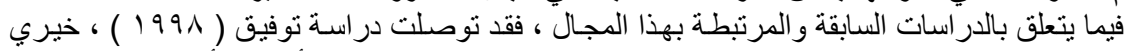

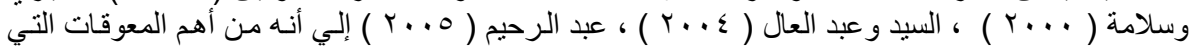




\section{Al-Gamal , M. M. A. et al.}

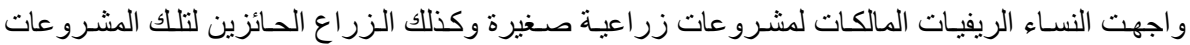

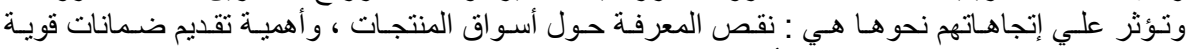

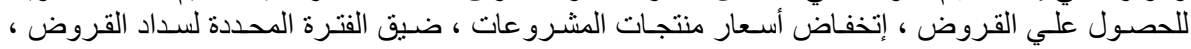

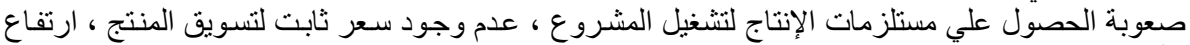

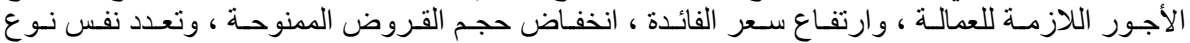
المشروع داخل القرية الواحدة.

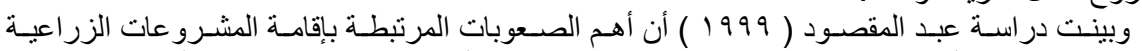

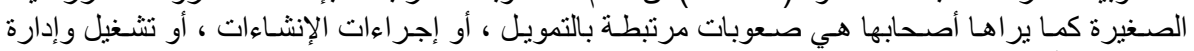
المشروع ، أو تصريف المغيا المنتجات.

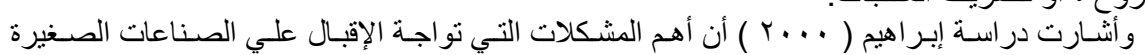

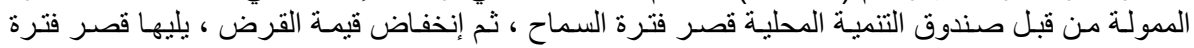

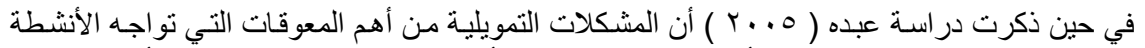

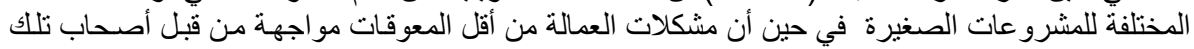
المشرو عات.

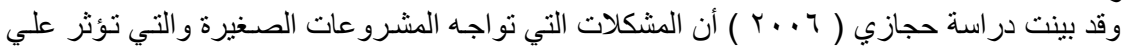

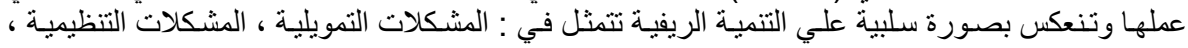

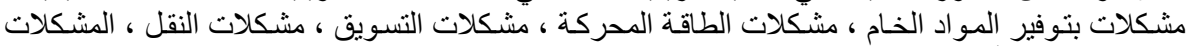

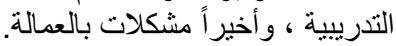

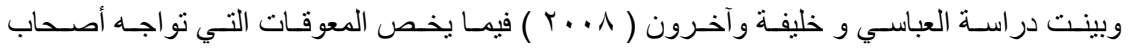

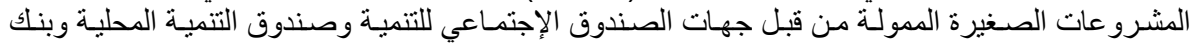

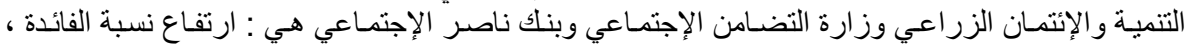

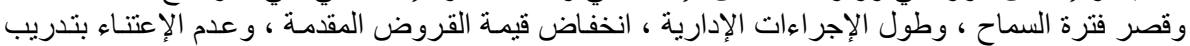

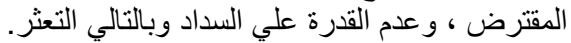

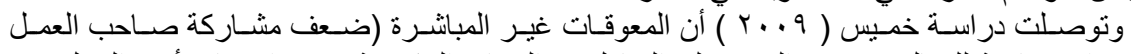

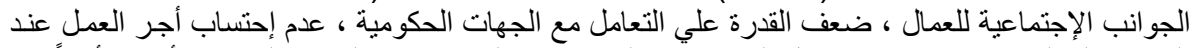

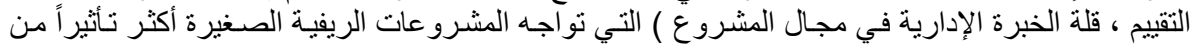

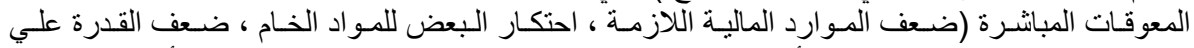

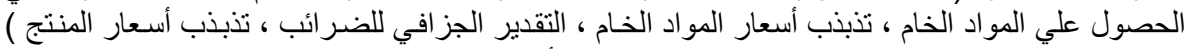

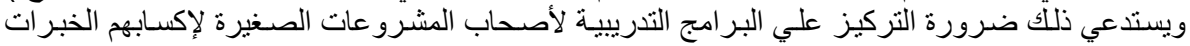

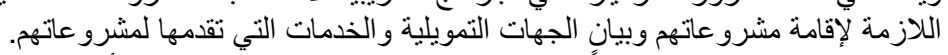

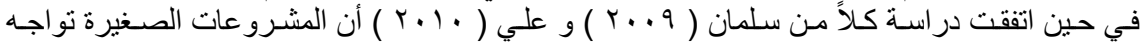

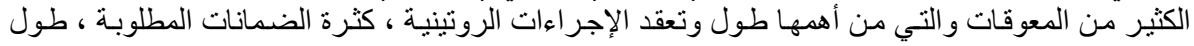

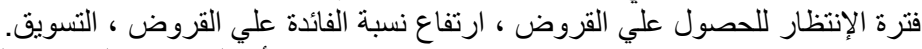

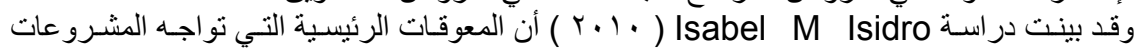

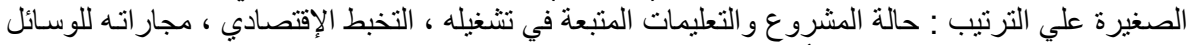

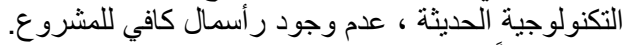

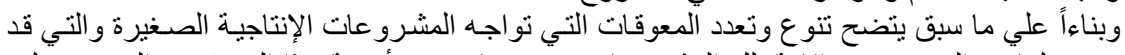

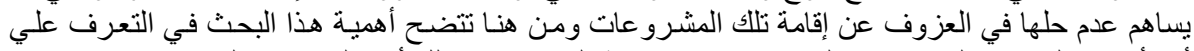

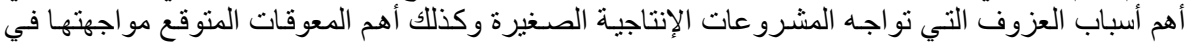
تللك الشرروعات في حالة إقامتها من قبل النساء الريفيات غير العاملاتهات عينة الدراسة.

\section{الطريقة البحثية}

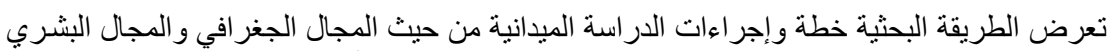

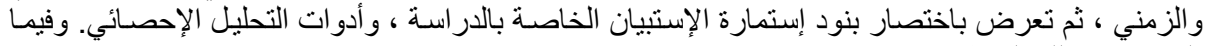
يلي عرض نلك النقاط : 


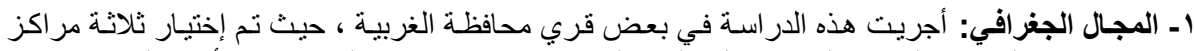

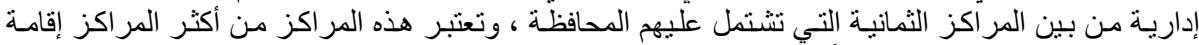

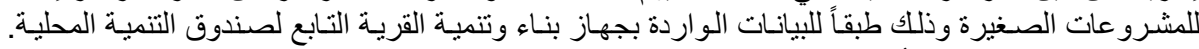

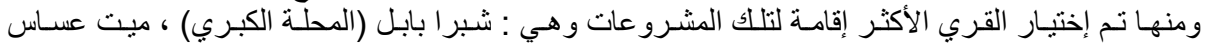

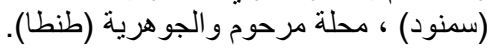

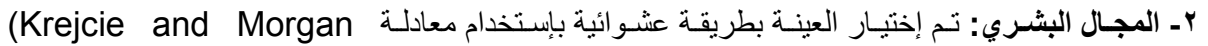

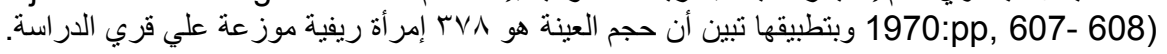

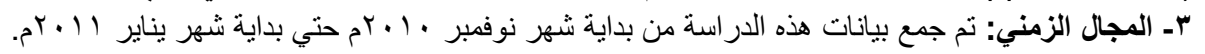

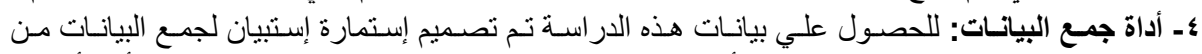

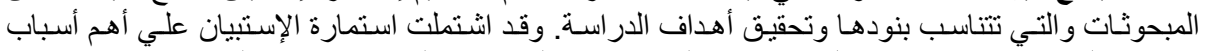

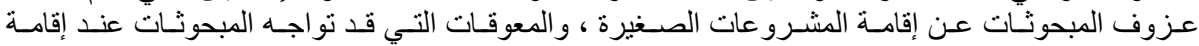

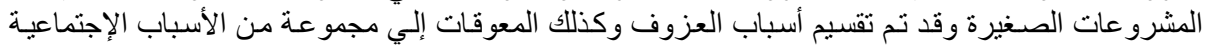
و الإدارية و المالية و الفنبة و التسويقية وأنية وأسباب أخري.

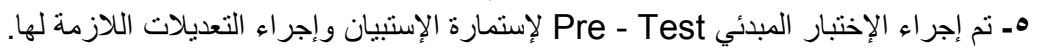

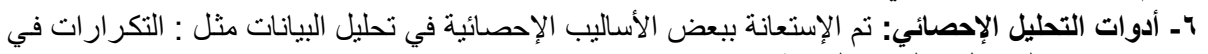

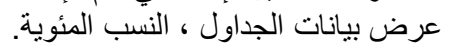

\section{النتائج ومناقشتها}

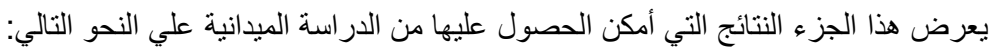

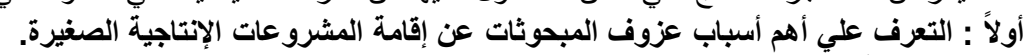

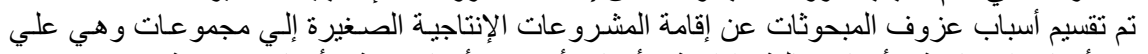

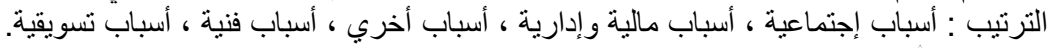

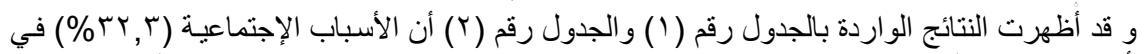

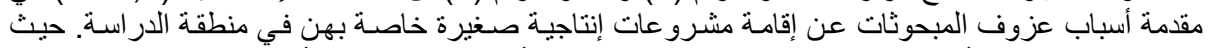

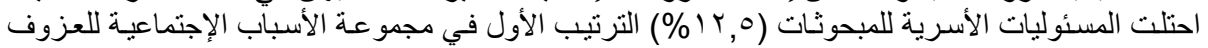

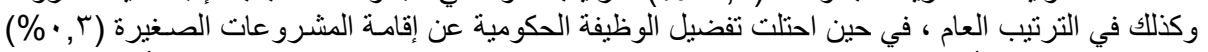

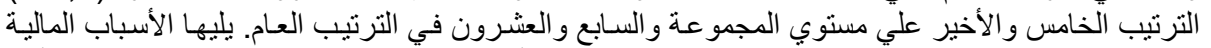

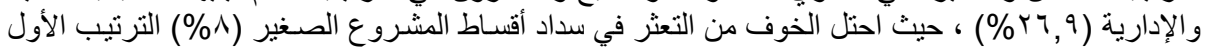

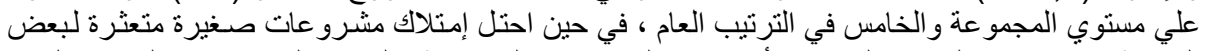

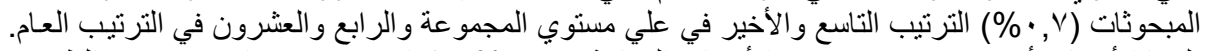

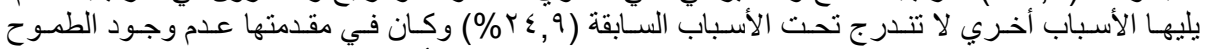

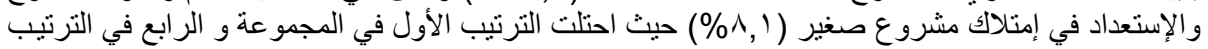

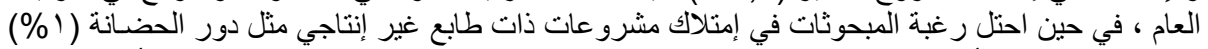

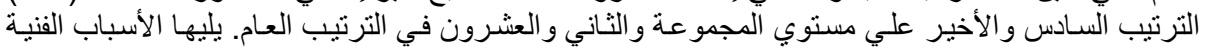

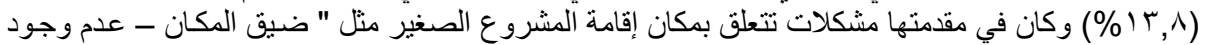

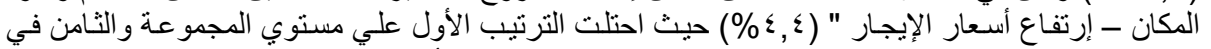

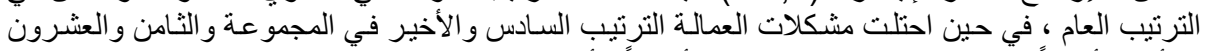

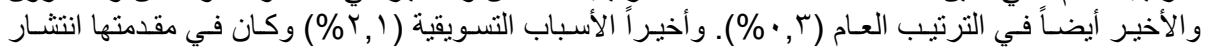

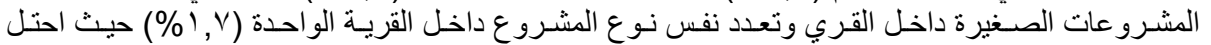

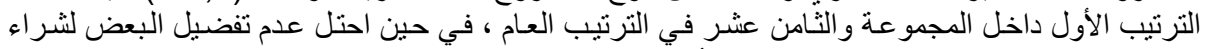

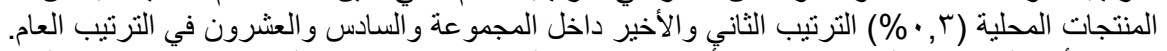

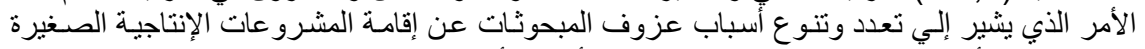

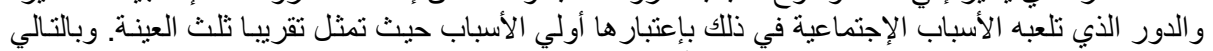

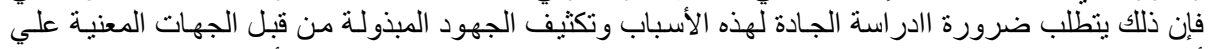

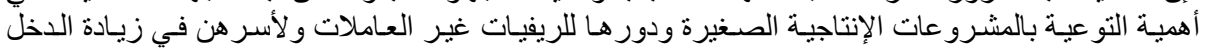

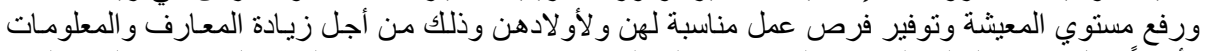

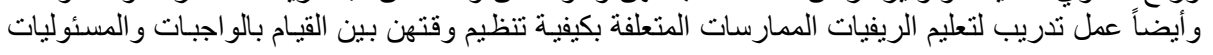


Al-Gamal , M. M. A. et al.

الأسرية و إدارة ومتابعة مشرو عاتهن الإنتاجية الصغيرة واقتر اح تلك الجهات لمشرو عات إنتاجية صغيرة لا لإنية تتعارض مع قيام المبحوثات بالتز اماتهن الأسرية. جدول (1) : توزيع المبحوثات وفقاً لمجموعات أسباب العزوف عن إقامة العبة المشروعات الإتتاجية الصغيرة

\begin{tabular}{|c|c|c|}
\hline$\%$ & 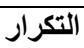 & أسباب العزوف مقسمة في مجموعات \\
\hline$r, r$ & 97 & | الأسباب الإجتماعية. \\
\hline$r 7,9$ & $\wedge$. & | - الأسباب المالية و الإدارية. \\
\hline$r \leqslant, 9$ & $V \varepsilon$ & | آـ أسباب أخري. \\
\hline $1 r, \Lambda$ & $\leqslant 1$ & عـ الأسباب الفنية. \\
\hline$r, 1$ & 7 & |مـ الأسباب التسويقية. \\
\hline $1 \cdots$ & rqV & |الإجـــالي \\
\hline
\end{tabular}

جدول (r) : توزيع المبحوثات وفقاً لأهم أسباب عزوفهن عن إقامة مشروعات إنتاجية صغيرة

\begin{tabular}{|c|c|c|c|c|}
\hline الترتيب & المجموعة التيب داخل & $\%$ & 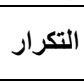 & أسباب العزوف \\
\hline 1 & 1 & Ir,o & TV & 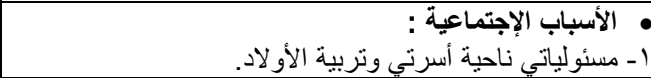 \\
\hline r & r & $9, \wedge$ & rq & r- مرتب زوجي كويس وبيكفينا ومش محتاجة للمشروع \\
\hline$r$ & $r$ & 9,1 & TV & ب- زوجي - حذ من أفراد أسرتي ممكن برفض إن اعمل مشروع. \\
\hline ro & $\varepsilon$ & $\cdot, \mathrm{V}$ & $r$ & ـ - مفيش تشجيع من اللي حو اليا يخليني افكر ان اعمل مشروع. \\
\hline TV & 0 & $\cdot, r$ & 1 & هـ الوظيفة الحكومية أحسن ومضمونة عن أي مشروع \\
\hline & & $r, r$ & 99 & الإجـــالي \\
\hline
\end{tabular}

تابع جدول (r) : توزيع المبحوثات وفقاً لأهم أسباب عزوفهن عن إقامة مثروعات إنتاجية صغيرة

\begin{tabular}{|c|c|c|c|c|}
\hline الترامٍ & | الترتيب داخل & $\%$ & 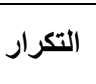 & أسباب العزوف \\
\hline 0 & 1 & $\wedge, 1$ & r纟 & 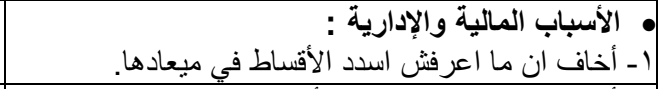 \\
\hline 7 & $r$ & $7, \varepsilon$ & 19 & 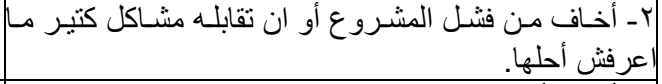 \\
\hline $1 \cdot$ & $r$ & $r, \mathrm{~V}$ & 11 & بـ أخاف أن سعر الفائدة يكون كبير علي القرض \\
\hline 10 & $\varepsilon$ & $r, \varepsilon$ & V & وظايف محددة. \\
\hline 17 & 0 & Y & 7 & 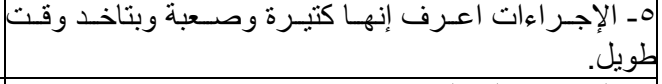 \\
\hline 19 & 7 & $1, \mathrm{~V}$ & 0 & فلوس كتير. الصرف علي المشروع بيكون صعب في بدايته وبيحتاج \\
\hline$r$. & V & 1 & $r$ & 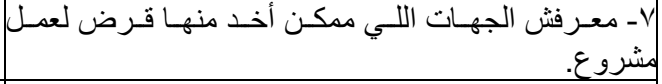 \\
\hline YI & $\Lambda$ & 1 & $r$ & 1- القروض اللي بتتاخد معظمها صغيرة وما تكفيش. \\
\hline$r \varepsilon$ & 9 & $\because, \mathrm{V}$ & Y & 9- كنت عاملة مشروع قبل كده وفشل وخسرت فلوس كتير . \\
\hline
\end{tabular}


J. Agric. Econom. and Social Sci., Mansoura Univ., Vol.3 (7), July, 2012

\begin{tabular}{|c|c|c|c|c|}
\hline & & $r q, 9$ & $\Lambda$ & الإجـــالي \\
\hline$\varepsilon$ & 1 & 9 & TV & • أسباب أخري : 1 استعداد إني اعمل مشرو ع أو أديره بنفسي. \\
\hline V & r & 0 & 10 & توفر لي شغل كويس. شايدة للمشرو عات دي في انها تزود دخل او \\
\hline 11 & $r$ & $r, \mathrm{~V}$ & 11 & rا - مفيش مشروع معين بفكر اني اعمله. \\
\hline IT & $\varepsilon$ & $r$ & 9 & ع - مش مضمونة و مشاكلها كتير. \\
\hline 14 & 0 & $r$ & 9 & |ـ الأسرة تملك مشروع وساعات بشتغل فيه. \\
\hline YY & 7 & 1 & $r$ & 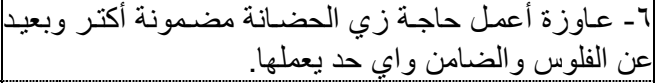 \\
\hline & & $r \leqslant, q$ & $V \leq$ & |الإجمـالي \\
\hline$\wedge$ & 1 & $\varepsilon, \varepsilon$ & $1 \pi$ & 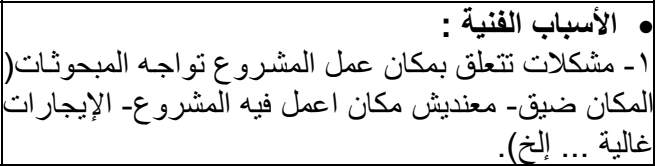 \\
\hline 9 & r & $\varepsilon$ & Ir & ب - معنديش خبرة كافية لعمل المشروع. \\
\hline $1 \varepsilon$ & $r$ & $r, \varepsilon$ & $\mathrm{V}$ & rr- مفيش عندي وقت اعمل به مشروع و الأهم ان اتابعه. \\
\hline
\end{tabular}

تابع جدول (r) : توزيع المبحوثات وفقاً لأهم أسباب عزوفهن عن إقامة مشروعات إنتاجية صغيرة

\begin{tabular}{|c|c|c|c|c|}
\hline التُرتيب & 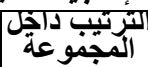 & $\%$ & 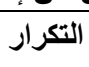 & أسباب العزوف \\
\hline IV & $\varepsilon$ & r & 7 & 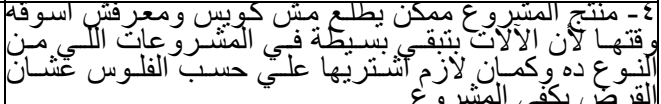 \\
\hline TT & 0 & $\therefore, \mathrm{V}$ & $T$ & 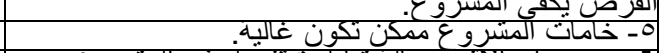 \\
\hline$T$ & 7 & $\operatorname{trin}$ & 81 & 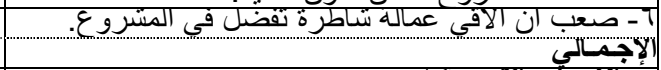 \\
\hline 11 & 1 & $1, v$ & 0 & 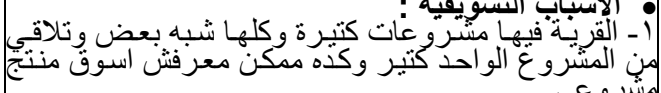 \\
\hline rY & r & $\cdot, r$ & 1 & 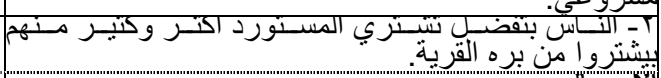 \\
\hline & & $\frac{1}{19}$ & Tav & \\
\hline
\end{tabular}

ثانياً : التعرف علي أهم المعوقات المتوقعة عند إقامة المبحوثات لمشروعات إنتاجية صغيرة خاصة بهن.

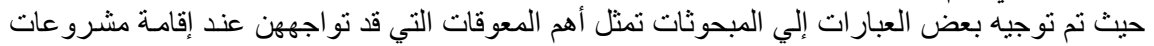

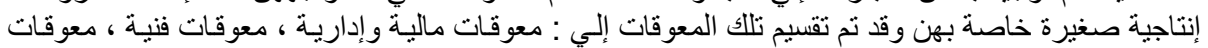

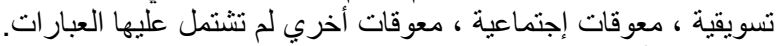

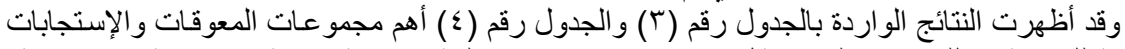

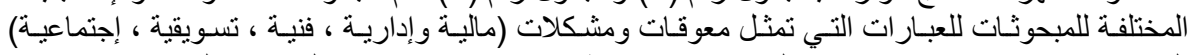

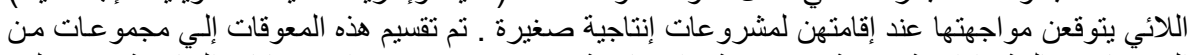

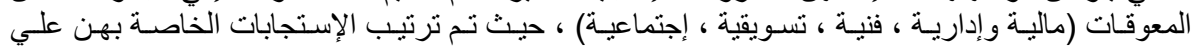




\section{Al-Gamal , M. M. A. et al.}

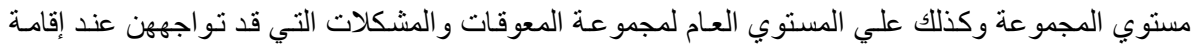

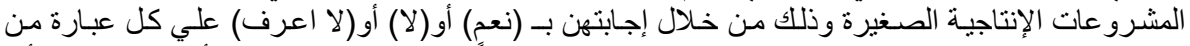

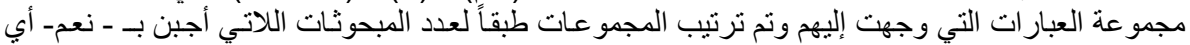

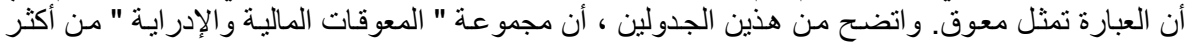

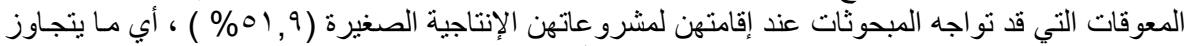

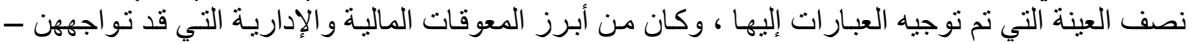

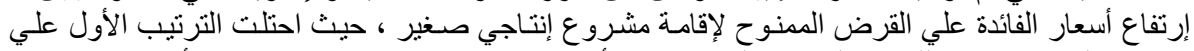

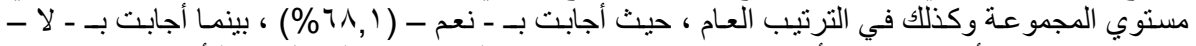

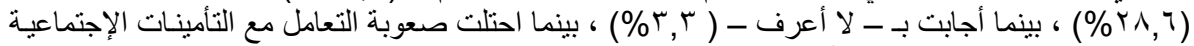

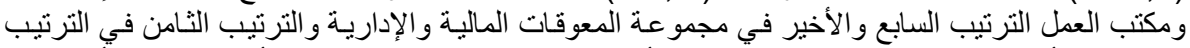

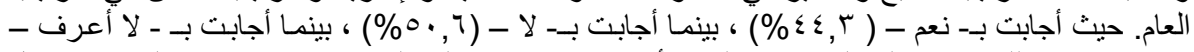

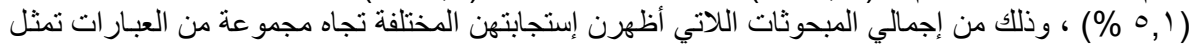

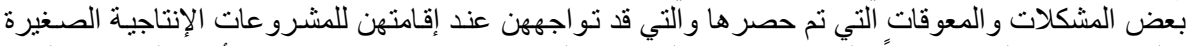

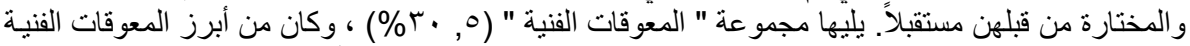

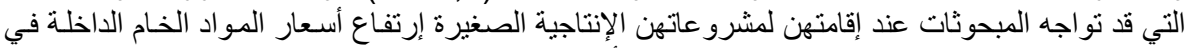

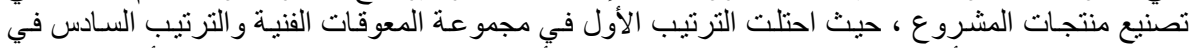

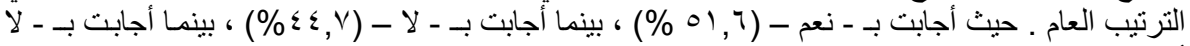

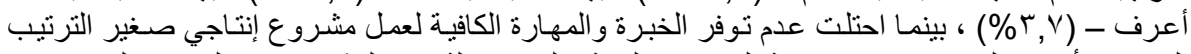

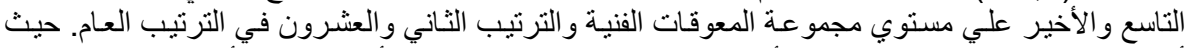

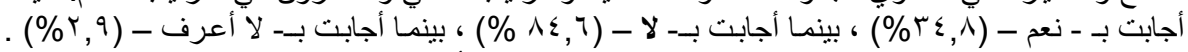

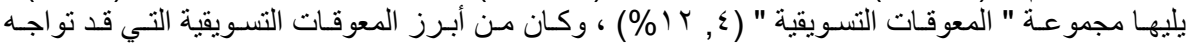

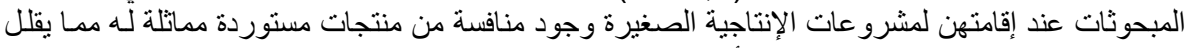

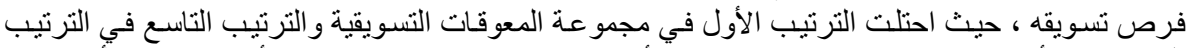

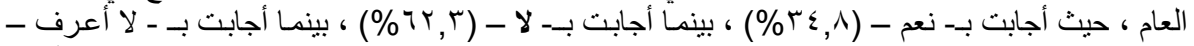

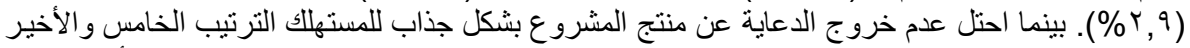

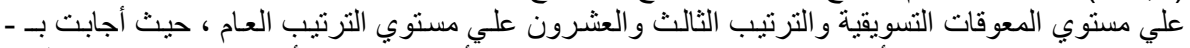

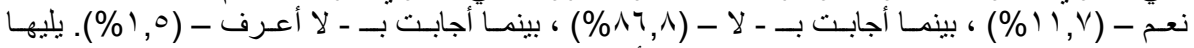

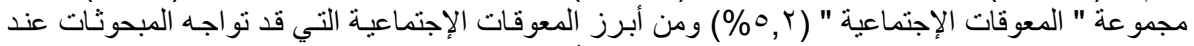

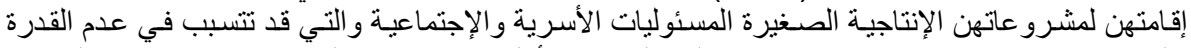

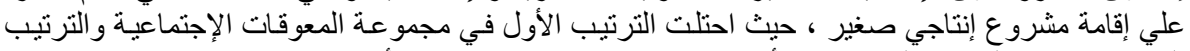

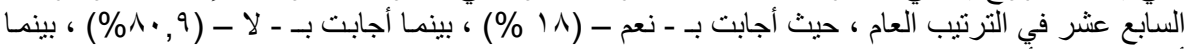

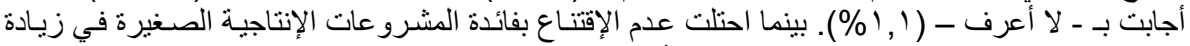

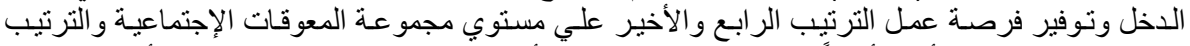

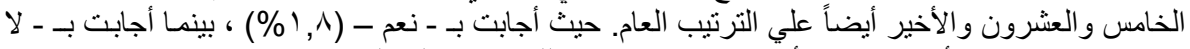

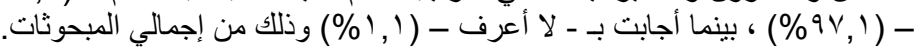

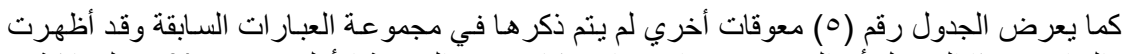

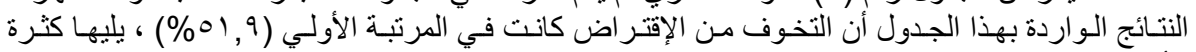

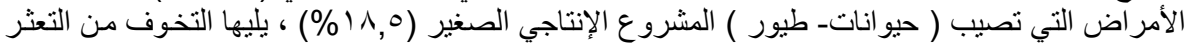

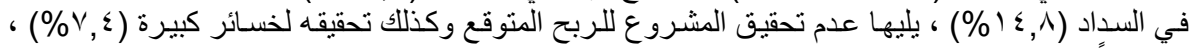

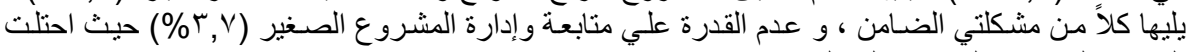
الترتيب الخامس و النسادس علي الترتيب.

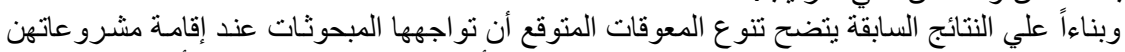

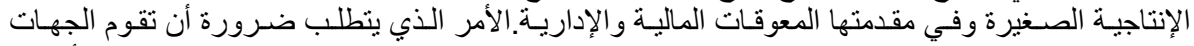

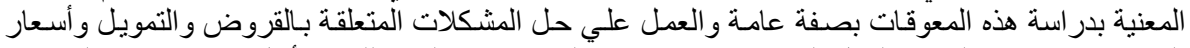

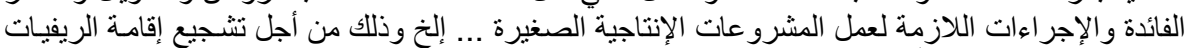




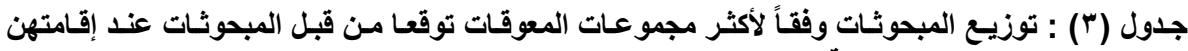

ل المشروعات إنتاجية صغيرة

\begin{tabular}{|c|c|c|}
\hline$\%$ & آنكرار & مجمو عات المعوقهات \\
\hline 01,9 & +9 & 1- المعوفات الماليه والإداريهي. \\
\hline 1\%, & TूT & 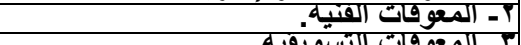 \\
\hline $0, i$ & 1.7 & 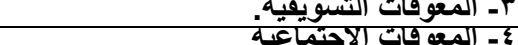 \\
\hline $1 \cdots$ & 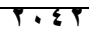 & الإجهــالى \\
\hline
\end{tabular}

جدول (؛ ) : توزيع المبحوثات وفقاً لإستجابتهن للمشكلات والمعوقات المتوقع مواجهتها عند

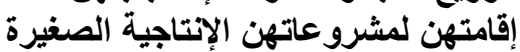

\begin{tabular}{|c|c|c|c|c|c|c|c|c|c|c|}
\hline \multirow{3}{*}{$\%$} & \multirow{3}{*}{ 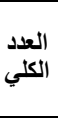 } & \multirow{3}{*}{ الت الترتيب } & \multirow{3}{*}{ الترتيب } & \multicolumn{6}{|c|}{ 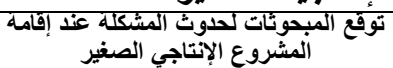 } & \multirow{3}{*}{ المعوقات أو المشكلات المطروحة علي المبحوثات } \\
\hline & & & & \multicolumn{2}{|c|}{ لا اعرف } & \multicolumn{2}{|c|}{$\bar{\gamma}$} & \multicolumn{2}{|c|}{ نَعـم } & \\
\hline & & & & $\%$ & 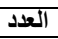 & $\%$ & 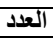 & $\%$ & 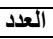 & \\
\hline $1 \cdots$ & TVT & 1 & 1 & r, & 9 & 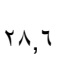 & VA & 71,1 & 114 & اللي ممكن \\
\hline $1 \ldots$ & TVT & r & r & $r, r$ & 9 & $r \leqslant, \wedge$ & 90 & 71,9 & 179 & 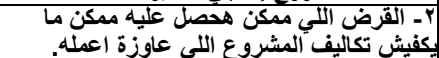 \\
\hline $1 \ldots$ & TVT & $r$ & r & 0,1 & $1 \leq$ & $r \uparrow, 7$ & $1 \cdots$ & $\Delta \wedge, r$ & 109 & تصغير. تصيلات الكافية لو \\
\hline $1 \cdots$ & TVT & $\varepsilon$ & $\varepsilon$ & $r, \mathrm{~V}$ & $1 \cdot$ & $r 9,0$ & $1 \cdot 1$ & 07,1 & 100 & ــ الخوف من ارتفاع الضرَائب علي المشروع. \\
\hline $1 \ldots$ & TVT & 0 & 。 & 0,1 & $1 \leqslant$ & $\leqslant r, 1$ & 110 & or,$\wedge$ & $1 \leq \varepsilon$ & 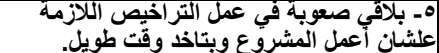 \\
\hline $1 \ldots$ & TVT & V & 7 & 1,1 & 0 & or & $1 \leqslant r$ & $\varepsilon 7, Y$ & 1K4 & 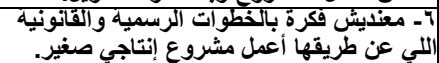 \\
\hline $1 \ldots$ & TVT & $\wedge$ & V & 0,1 & $1 \leq$ & $0 \cdot, 7$ & $1 \mathrm{k}$ & $\varepsilon \varepsilon, \Gamma$ & $|r|$ & d \\
\hline
\end{tabular}

تـابع جدول (؛ ) : توزيع المبحوثات وفقاً لإستجابتهن تجـاه المشكلات والمعوقات المتوقع مواجهتها عنــ

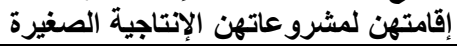

\begin{tabular}{|c|c|c|c|c|c|c|c|c|c|c|}
\hline \multirow{3}{*}{$\%$} & \multirow{3}{*}{ الكليد } & \multirow{3}{*}{ التُاميب } & \multirow{3}{*}{ المجزتزب } & \multicolumn{6}{|c|}{ 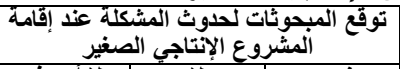 } & \multirow{3}{*}{ المعوقات أو المشكلات المطروحة علي } \\
\hline & & & & \multicolumn{2}{|c|}{ لا أعرف } & \multicolumn{2}{|c|}{$y$} & \multicolumn{2}{|c|}{ نسعم } & \\
\hline & & & & $\%$ & العلد & $\%$ & الكعد | العد & $\%$ & العلدد & \\
\hline $1 \ldots$ & TVT & 7 & 1 & $r, v$ & 1. & $\varepsilon \varepsilon, \mathrm{V}$ & IYT & 01,7 & $1 \leqslant 1$ & تصنيع متفجات ألمشر" الموز \\
\hline $1 \cdots$ & TVT & 1. & T & 9,0 & r4 & $07, \wedge$ & 100 & re, , & 94 & 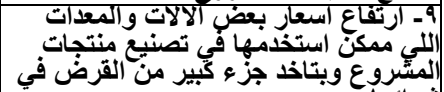 \\
\hline $1 \cdots$ & TVT & 11 & r & $r, r$ & 7 & TV & INT & $r \cdot, \wedge$ & $\wedge \varepsilon$ & 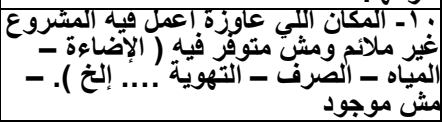 \\
\hline $1 \cdots$ & TVT & IT & $\varepsilon$ & 11 & $r \cdot$ & $7 \leqslant, 0$ & $1 V 4$ & $Y \leqslant, 0$ & TV & 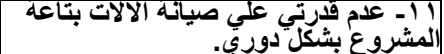 \\
\hline $1 \cdots$ & TVT & 15 & 0 & $11, \mathrm{~V}$ & Tr & $77, y$ & INT & $r 1,7$ & 09 & 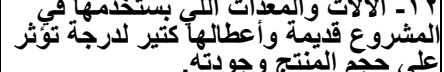 \\
\hline $1 \cdots$ & TVT & $1 \varepsilon$ & 7 & $\varepsilon, \varepsilon$ & IT & $V \varepsilon, V$ & $r \cdot \varepsilon$ & $r \cdot, 9$ & ov & 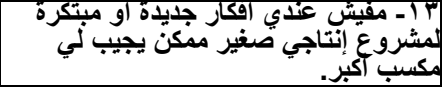 \\
\hline
\end{tabular}

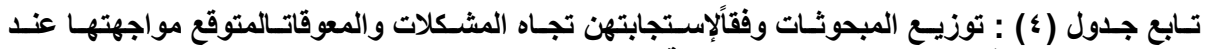
إقامتهن لمشروع المبحونات الإنتاجية الصغيرة

\begin{tabular}{|c|c|c|c|c|c|c|c|}
\hline \multirow[t]{2}{*}{$\%$} & \multirow{2}{*}{ 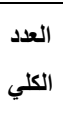 } & \multirow{2}{*}{ | التعائ } & \multirow{2}{*}{ المجموعة الترتيب } & \multicolumn{3}{|c|}{ 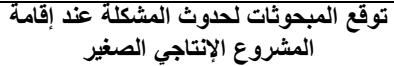 } & \multirow{2}{*}{ المعوقات أو المشكلات المطروحة علي } \\
\hline & & & & لا أعرف & $y$ & نسعم & \\
\hline
\end{tabular}


Al-Gamal , M. M. A. et al.

\begin{tabular}{|c|c|c|c|c|c|c|c|c|c|c|}
\hline $1 \ldots$ & TVT & 11 & V & $r, v$ & 1. & $v 9, \lambda$ & 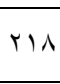 & 17,0 & $\leq 0$ & |الملائم الإحتياجات الإهتمام بتحسين المنتج بالثكل \\
\hline $1 \ldots$ & TVT & 19 & $\wedge$ & $\varepsilon$ & 11 & $v 9,0$ & $Y \backslash V$ & 17,0 & $\leqslant 0$ & صعب عليا أسوقة. 10 ـ انخفة المنتج وبالتالي هيبقي \\
\hline $1 \cdots$ & TVT & rY & 9 & $r, r$ & 9 & $A \varepsilon, T$ & וTr & $\mid r, 1$ & r & |عمل مشروع إنتاجي صغير. 17 - معنديش الخبرة المطلوبة \\
\hline $1 \cdots$ & TVT & 9 & 1 & $r, q$ & $\wedge$ & $\pi, \Gamma$ & IV. & $r \varepsilon, \lambda$ & 90 & 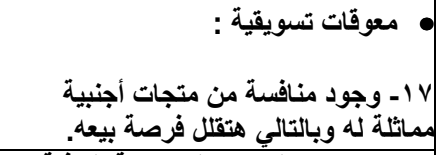 \\
\hline $1 \ldots$ & TVT & 10 & r & 1,1 & 0 & $\vee \wedge, \wedge$ & $\$ 10$ & $19, \varepsilon$ & or & لبيع منتجات المشروع المهارة التسويقية الكافية الصغير. \\
\hline $1 \ldots$ & TVT & 17 & $r$ & 1,0 & $\varepsilon$ & $\Lambda \cdot, r$ & Y19 & $1 \wedge, r$ & 0. & 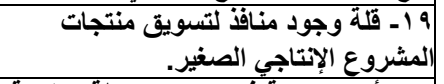 \\
\hline $1 \ldots$ & TVT & rI & $\varepsilon$ & 1,0 & $\varepsilon$ & $\wedge \uparrow, \varepsilon$ & דr & $\mid r, 1$ & r & 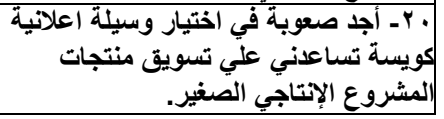 \\
\hline
\end{tabular}

تابع جدول (؛ ) : توزيع المبحوثات وفقاً لإستجابتهن تجـاه المثكلات والمعوقات المتوقع مواجهتها عند

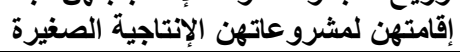

\begin{tabular}{|c|c|c|c|c|c|c|c|c|c|c|}
\hline \multirow[t]{3}{*}{$\%$} & \multirow{3}{*}{ 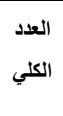 } & \multirow{3}{*}{ الترتيب } & \multirow{3}{*}{ المجموتزي } & \multicolumn{6}{|c|}{ توقع المبحوثات لحدوث الإنتاجي الصغلة عند إقامة } & \multirow{3}{*}{ المعوقات أو المشكلات المطروحة علي } \\
\hline & & & & \multicolumn{2}{|c|}{ لا أعرف } & \multicolumn{2}{|c|}{$y$} & \multicolumn{2}{|c|}{ نسع } & \\
\hline & & & & $\%$ & العلد & $\%$ & العلد & $\%$ & العدد & \\
\hline $1 \ldots$ & TVT & Tr & 0 & 1,0 & $\varepsilon$ & $\wedge \uparrow, \wedge$ & TrV & $11, \mathrm{v}$ & Tr & |بشكل يجذب خروج المستهلك. \\
\hline $1 \ldots$ & TVT & IV & 1 & 1,1 & $r$ & $\Lambda \cdot, q$ & $\mid Y_{1}$ & 11 & $\leqslant 9$ & 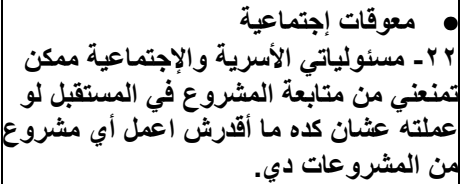 \\
\hline $1 \ldots$ & TVT & $r$. & r & 1,1 & $r$ & $\Delta r, \lambda \mid$ & TYY & 17,1 & $\varepsilon \varepsilon$ & مشروع إنتاجي صغير. \\
\hline $1 \ldots$ & TVT & $r \leq$ & $r$ & 1,1 & $r$ & 97 & YTY & $r, q$ & $\wedge$ & إنتاجي صغ أنا مغنديش استعداد اعمل أي مشروع \\
\hline $1 \ldots$ & TVT & ro & 㲅 & 1,1 & $r$ & $9 \vee, 1$ & r7o & $1, \wedge$ & 0 & 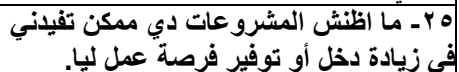 \\
\hline
\end{tabular}

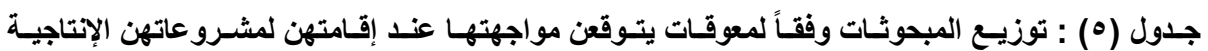
الصغيرة

\begin{tabular}{|c|c|c|}
\hline$\%$ & التتكرار & الـــــــوقات \\
\hline 01,9 & $1 \leq$ & 1- خايفة من موضوع القروض ومشاكلها \\
\hline 11,0 & o & r- الطيور - الحيوانات ممكن يجي لها أمراض ويموت منها كتير. \\
\hline $1 \varepsilon, \wedge$ & $\varepsilon$ & r- خايفة ما اقرش اسدد الأقساط في مواعيدها \\
\hline$v, \varepsilon$ & r & أخسارة .... ألخ ). \\
\hline
\end{tabular}




\begin{tabular}{|c|c|c|}
\hline$r, v$ & $T$ & هـ الضامن. \\
\hline$r, \mathrm{r}$ & 1 & ل- مـا اقدرش اني اتابع المشروع لو عملته. \\
\hline $1 \ldots$ & TV & الإجـــالي \\
\hline
\end{tabular}

الخلاصة و التوصيات

بناءاً علي النتائج البحثية يمكن التوصية بما يلي :

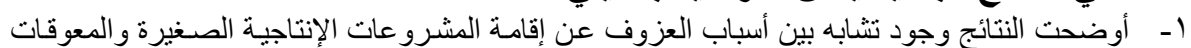

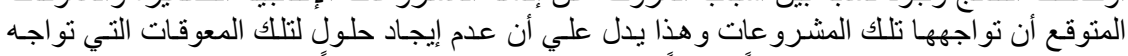

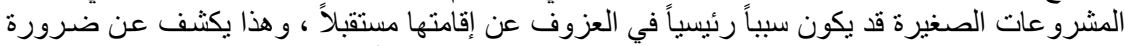

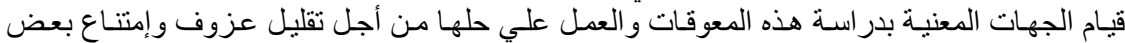

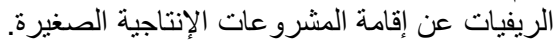

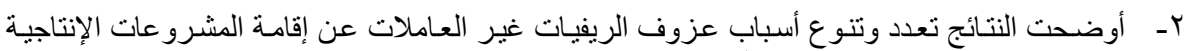

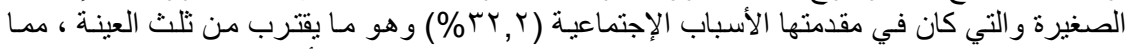

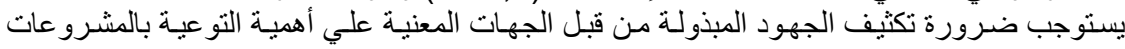

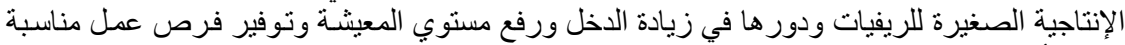

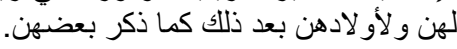

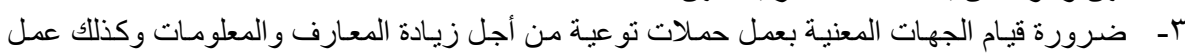

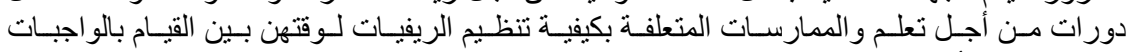

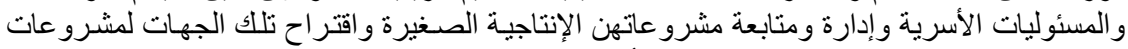

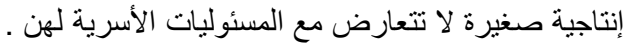

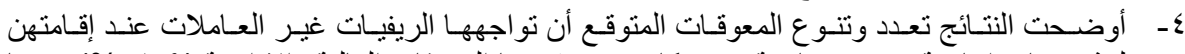

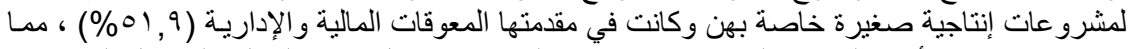

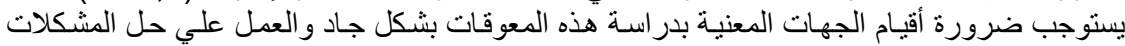

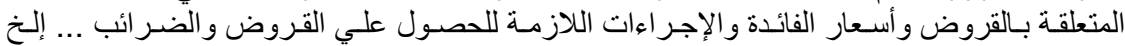
و العمل علي حلها وذللك من أجل تشجيع إقامة الريفيات للمشرو عات الإنة الإنتاجية الصغيرة.

$$
\text { المراجع }
$$

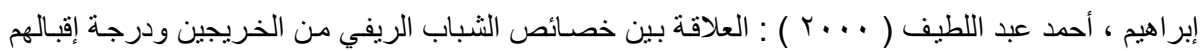

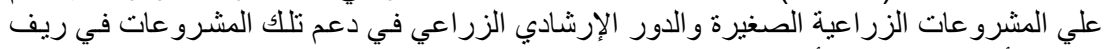

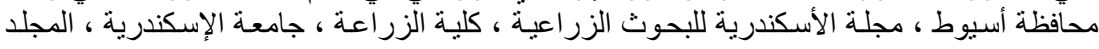

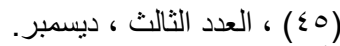

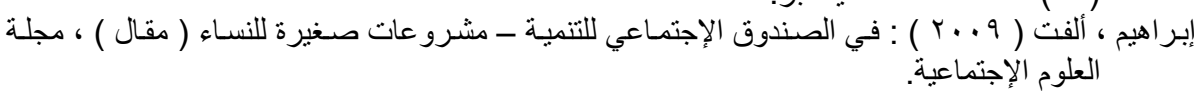
http://www.swmsa.net/article.php?action=show \&id=467

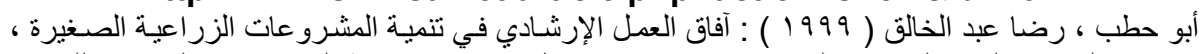

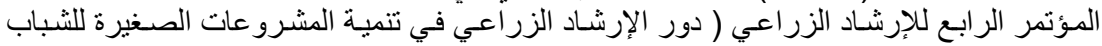

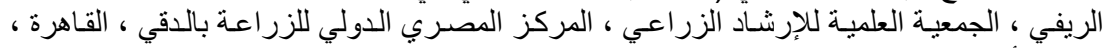

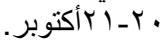

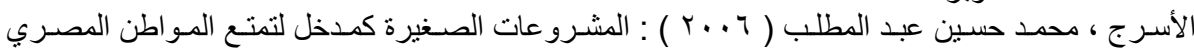

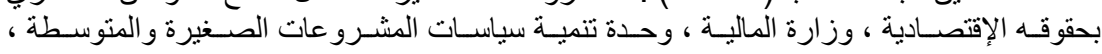

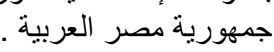

http://www.sme.gov.eg/papers/SMEs_PPI_Econ.pdf

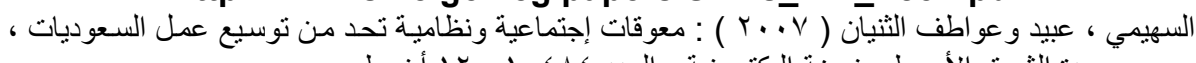

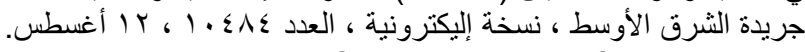

http://www.aawsat.com/details.asp?article=432242\&issueno=10484 


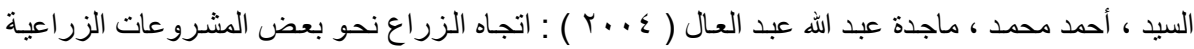

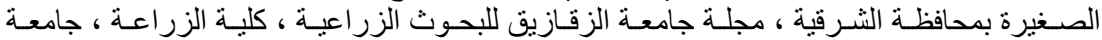

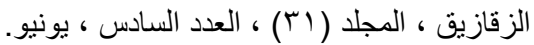

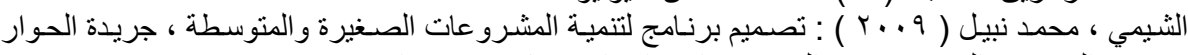

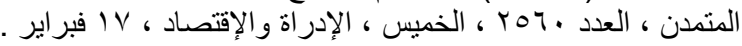

http://www. ahewar.org/debat/show.art.asp?aid=163083

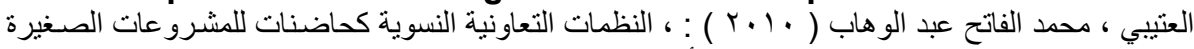

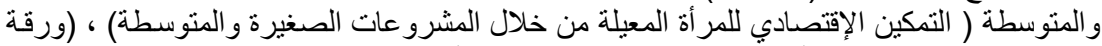

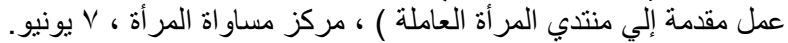

http://www.c-we.org/ar/art/show.art.asp?aid=218347

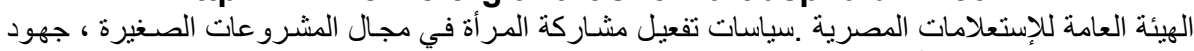
تعزيز واقع المر أة المصرية ، موقع إليكتروني.

http://www2.sis.gov.eg/Ar/Women/empowerment/100500000000000001. htm

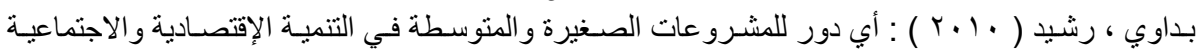
(مقال ) ، موقع إليكتروني.

http://www.tanmia.ma/article-imprim.php3?id_article=21325

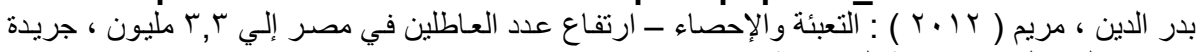
http://www.yom7.com/News.asp?NewsID=684012

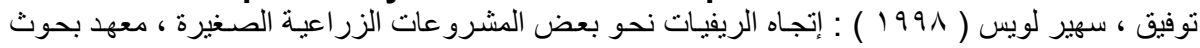

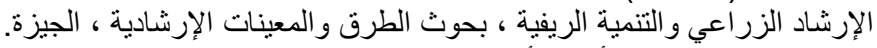

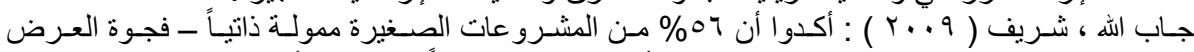

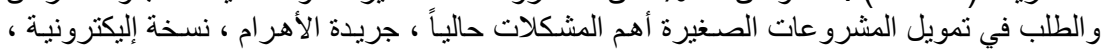

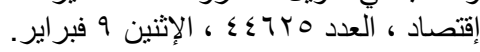

http://www.ahram.com.eg/archive/2009/2/9/ECONZ.HTM

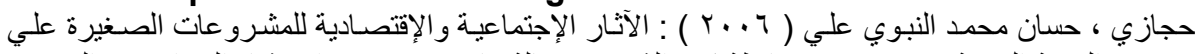

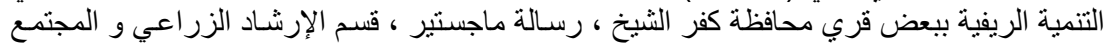

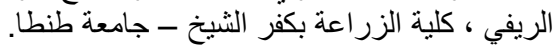

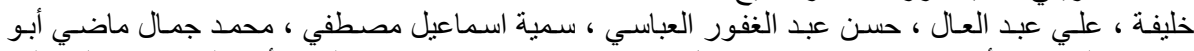

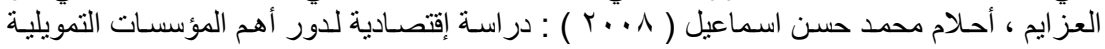

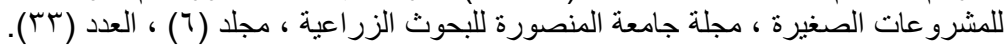

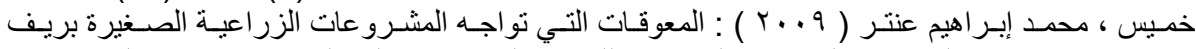

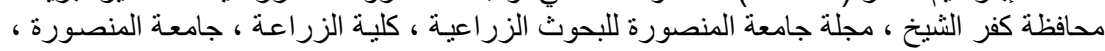

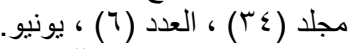

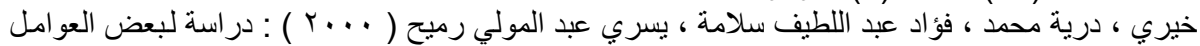

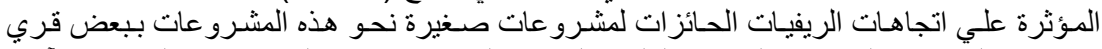

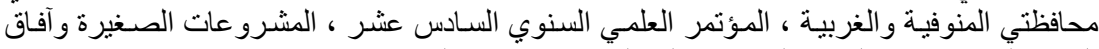

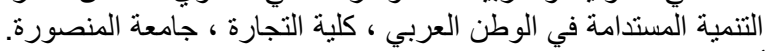

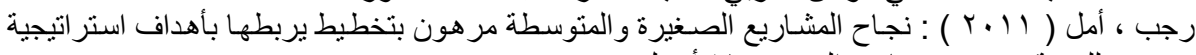
http:// www.omandaily.om/node/49897

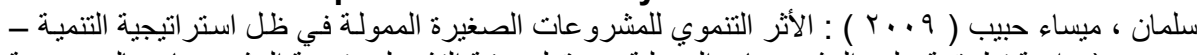

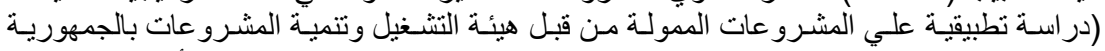

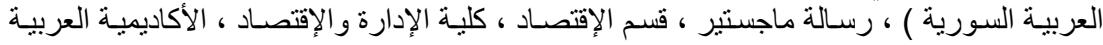
المفتوحة في الدانمارك. 


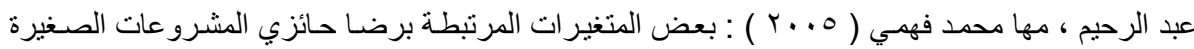

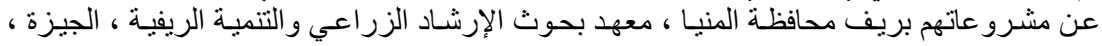

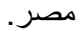

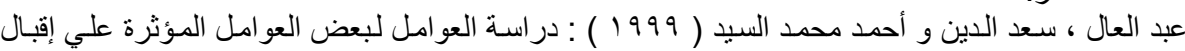

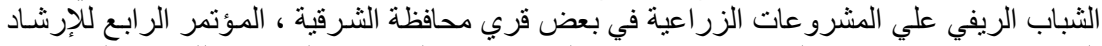

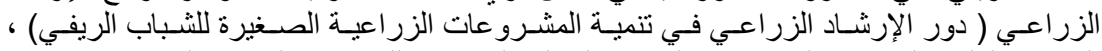

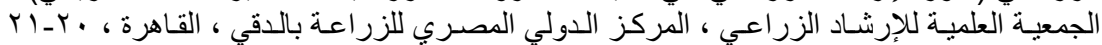
أكتوبر.

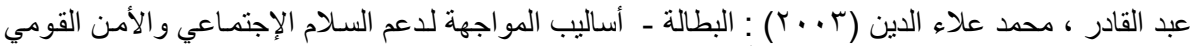

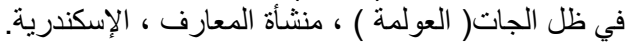

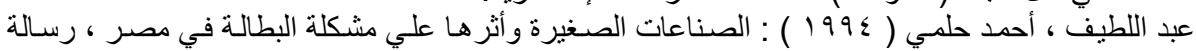

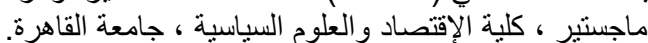

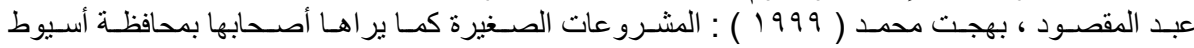

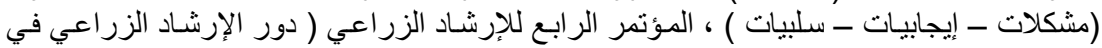

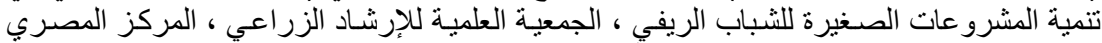

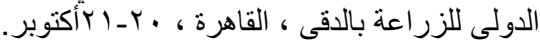

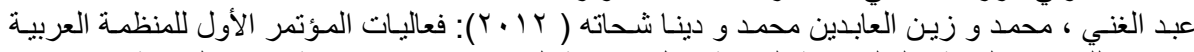

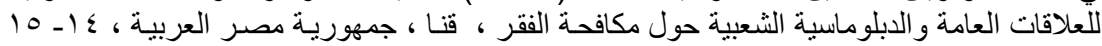

\section{http://www.aoprpd.com/news/129/Default.aspx}

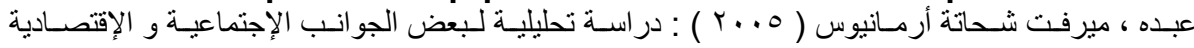

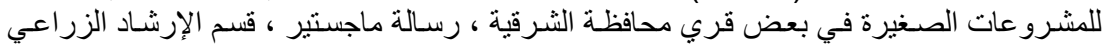

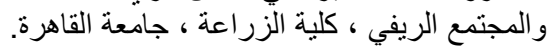

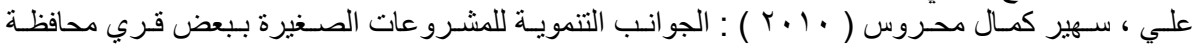

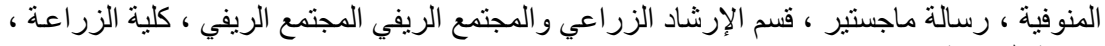
جامعة المنوفية.

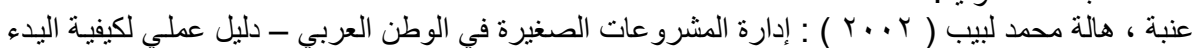

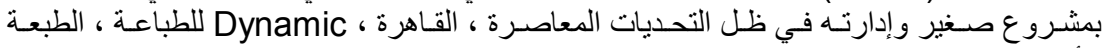
الأولي.

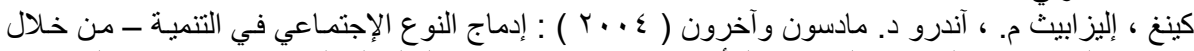

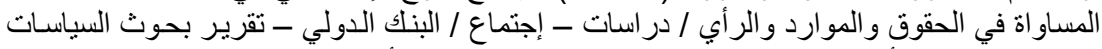

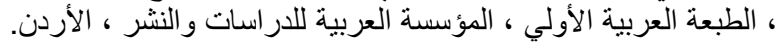

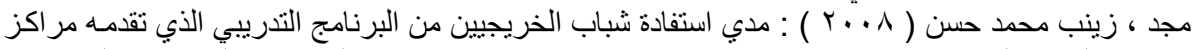

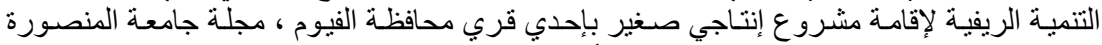

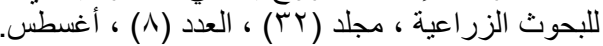

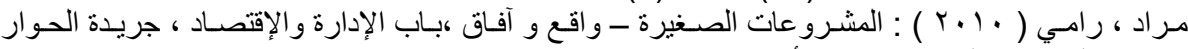

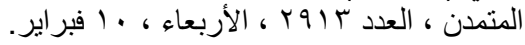

\section{http://www.ahewar.org/debat/show.art.asp?=0\&aid=202806}

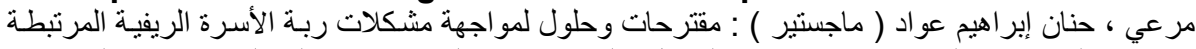

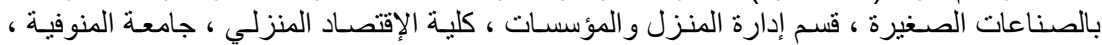

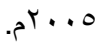

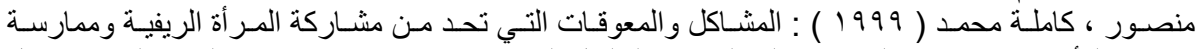

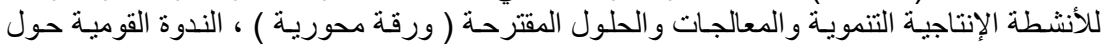

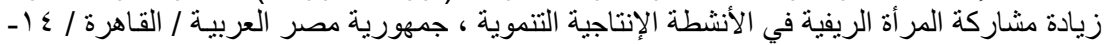

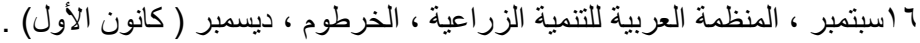

Krejcie , R .V and Morgan , D.W : Determining sample size for reasearch activities eductional and psychological measurement, college station Urham, north Carolina, 1970. 
Pleshette , Lyve Alexis , 8 Deadly Mistakes of Small Business , Power HomeBiz Guides, Making Small Business Do Big Business , 2010. http://www.powerhomebiz.com/vol90/mistakes.htm

Sullivan, Thomas $M$ and Chad Moutray , US Small Business Administration , Office Of Advocacy, The Small Business Economy , A Report to The President, United States Government Printing Office, Washington $2001,2004$.

http://www.sba.gov/advo/research/sb_econ2008

\title{
STUDY OF THE MAIN REASONS FOR THE RELUCTANCE AND OBSTACLES TO ESTABLISHMENT OF RURAL UNEMPLOYED FEMALES OF SMALL PROJECTS AT SOME VILLAGES IN GHARBIA GOVERNORATE
}

\author{
Al-Gamal , M. M. A. ; Rabab W. A. Ghozy and Sally I. M. Younes
}

Dept. Agric. Extension and Rural Development, Fac. Agric., Mans. Univ.

\section{ABSTRACT}

Small projects play an important role for income-generating because of their importance in the face of the problem of unemployment and provide job opportunities for various segments of society, but it face some obstacles that may limit their effectiveness and may lead then to want to increase in the future. And then targeted this research to identify the most important reasons for the reluctance and obstacles to the establishment of rural unemployed females of the small projects in some villages in Gharbia Governorate. To achieve this, has been selected three administrative centers as an area for study by one by selecting four villages : Shubra Babel (Mahala), meet Assas (Samanoud), Mahallet Marhom and Goharrya (Tanta). The sample was selected randomly using the equation Krejcie and Morgan and their application shows that the sample size 378 Researched. Data were collected from November 2011 until the beginning of January 2011 of the questionnaire respondents through personal interviews, after the initial test them and make some adjustments. The questionnaire included some questions about the reasons for the reluctance and the obstacles that have confronted when a small projects, has been used in the presentation and analysis of data tabular presentation loops and percentages.

The results showed that : there is a similarity between the reasons for reluctance to establish productive projects of small and obstacles to be confronted by the rural non-working at their residence for productive projects little of their own, which shows the shows the role of these constraints is that it may become a major cause of reluctance to establish such projects in the future. the most important reasons for reluctance to establish small productive projects were the social causes $(2.32 \%)$, followed by reasons of financial and managerial $(9.26 \%)$, followed by other reasons 
$(9.24 \%)$, followed by technical reasons $(8.13 \%)$, followed by marketing reasons $(1.2 \%)$. the most important obstacles faced by respondents expected that their stay at the productivity of their projects were small, respectively: financial and administrative constraints $(9.51 \%)$, technical constraints $(5.30 \%)$, marketing constraints $(4.12 \%)$, social constraints $(2,5 \%)$, other constraints did not include the phrases. The study recommends the need of small projects establihment supporting to study the reasons for reluctance to establish projects small and constraints expected in these projects closely and work to solve in order to encourage the establishment of rural small projects, as well as the need to intensify efforts by the authorities concerned on the importance of awareness-raising projects, production of small rural unemployed females and its role in increasing income and raising the standard of living and provide job opportunities for themselves and their children in the future and also the work of awareness-raising campaigns to increase knowledge and information work sessions in order to learn and practice rural women Time management and organize their time between doing duties and their responsibilities of family,In addition to manage and follow-up their small projects.

$$
\text { كلية الزراعة - جامعة المنصورة البحرة }
$$

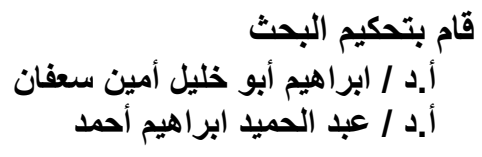

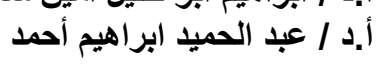

